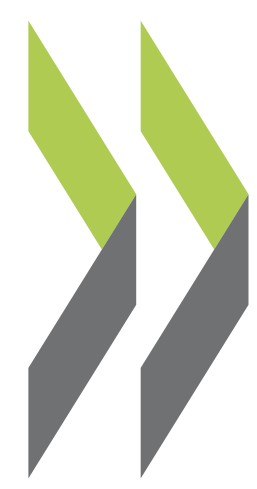

OECD Economics Department Working Papers No. 1554

Labour supply of older people in advanced economies: the impact of changes to statutory retirement ages
Christian Geppert,

Yvan Guillemette, Hermes Morgavi, David Turner 
LABOUR SUPPLY OF OLDER PEOPLE IN ADVANCED ECONOMIES: THE IMPACT OF CHANGES TO STATUTORY RETIREMENT AGES

ECONOMICS DEPARTMENT WORKING PAPER No. 1554

\section{By Christian Geppert, Yvan Guillemette, Hermes Morgavi and David Turner}

OECD Working Papers should not be reported as representing the official views of the OECD or of its member countries. The opinions expressed and arguments employed are those of the author(s).

Authorised for publication by Alain de Serres, Deputy-Director, Policy Studies Branch, Economics Department.

All Economics Department Working Papers are available at www.oecd.org/eco/workingpapers.

JT03448452 
OECD Working Papers should not be reported as representing the official views of the OECD or of its member countries. The opinions expressed and arguments employed are those of the author(s).

Working Papers describe preliminary results or research in progress by the author(s) and are published to stimulate discussion on a broad range of issues on which the OECD works.

Comments on Working Papers are welcomed, and may be sent to OECD Economics Department, 2 rue André Pascal, 75775 Paris Cedex 16, France, or by e-mail to eco.contact@oecd.org.

All Economics Department Working Papers are available at www.oecd.org/eco/workingpapers

On 25 May 2018, the OECD Council invited Colombia to become a Member. At the time of preparation, the deposit of Colombia's instrument of accession to the OECD Convention was pending and therefore Colombia does not appear in the list of OECD Members and is not included in the OECD zone aggregates.

This document and any map included herein are without prejudice to the status of or sovereignty over any territory, to the delimitation of international frontiers and boundaries and to the name of any territory, city or area.

The statistical data for Israel are supplied by and under the responsibility of the relevant Israeli authorities. The use of such data by the OECD is without prejudice to the status of the Golan Heights, East Jerusalem and Israeli settlements in the West Bank under the terms of international law.

\section{(C) OECD (2019)}

You can copy, download or print OECD content for your own use, and you can include excerpts from OECD publications, databases and multimedia products in your own documents, presentations, blogs, websites and teaching materials, provided that suitable acknowledgment of OECD as source and copyright owner is given. All requests for commercial use and translation rights should be submitted to rights@oecd.org 


\section{ABSTRACT/RESUMÉ \\ Labour supply of older people in advanced economies: the impact of changes to statutory retirement ages}

A decomposition of changes to participation rates of 55-to-74 year-olds between 2002 and 2017 based on an estimated equation attributes more than two thirds of the median increase (of 10.9 percentage points) to rising life expectancy and educational attainment. About 1 percentage point is attributable to changes in statutory retirement ages, although part of the reason these effects are not larger is that in most countries, statutory retirement ages have not kept pace with life expectancy. Although difficult to incorporate in the empirical framework, evidence of falling disability pension rolls and reduced sensitivity of old-age participation to the level of unemployment suggests that the tightening of alternative early retirement pathways through unemployment or disability schemes has been a major factor in the turnaround in the participation rate of older workers. Projections indicate that participation rates for 55-to-74 year-olds should keep rising through 2030, by 3.4 percentage points for the median country. Rising life expectancy and educational attainment are projected to make the largest contributions, more than compensating for the negative contribution of population ageing in most countries.

JEL codes: J21, J26

Keywords: Participation, labour supply, older workers, statutory retirement ages

$* * * * * * *$

\section{Offre de travail des plus âgés dans les économies avancées: l'impact des changements de l'âge légal de la retraite}

Une décomposition de l'évolution des taux d'activité des 55 à 74 ans entre 2002 et 2017 sur la base d'une équation estimée attribue plus des deux tiers de l'augmentation médiane (de 10,9 points de pourcentage) à la hausse de l'espérance de vie et du niveau d'instruction. Environ 1 point de pourcentage est attribuable aux modifications de l'âge légal de la retraite, ces effets n'étant pas plus importants en partie parce que, dans la plupart des pays, l'âge légal de la retraite n'a pas suivi le rythme de l'espérance de vie. Bien qu'il soit difficile d'incorporer ces canaux dans le cadre empirique, la baisse du nombre de retraites d'invalidité et la sensibilité réduite des taux d'activité au taux de chômage donnent à penser que le resserrement des possibilités de retraite anticipée grâce aux régimes de chômage ou d'invalidité a été un facteur majeur du redressement du taux d'activité des travailleurs âgés. Les projections indiquent que les taux de participation des 55 à 74 ans devraient continuer à augmenter jusqu'en 2030, de 3,4 points de pourcentage pour le pays médian. L'augmentation de l'espérance de vie et du niveau d'instruction devraient apporter les contributions les plus importantes, compensant largement la contribution négative du vieillissement de la population dans la plupart des pays.

Codes JEL: J21, J26

Mots-clés: Participation, offre de travail, travailleurs âgés, âge légal de retraite 


\section{Table of contents}

Labour supply of older people in advanced economies: the impact of changes to statutory retirement ages

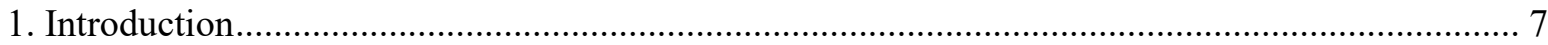

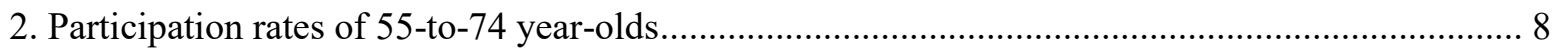

3. Drivers of participation rates for older people and results from previous studies ......................... 9

3.1. Potential drivers of change to participation rates of 55-to-74 year-olds ................................. 9

3.2. Disentangling the contribution of the potential drivers to the recent uptrend in participation

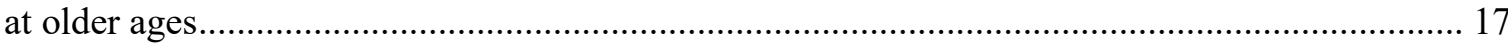

4. Empirical analysis of single-age participation rates for older people ............................................ 19

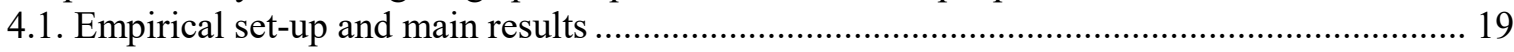

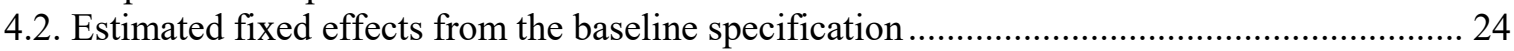

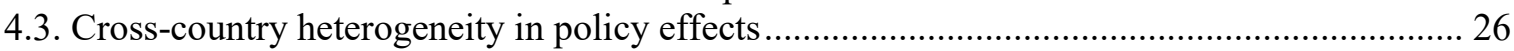

5. Historical decomposition and projection of participation rates for 55-to-74 year-olds using the

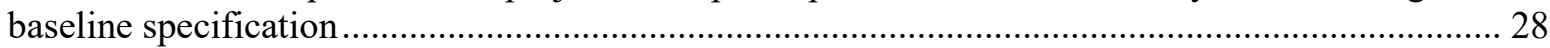

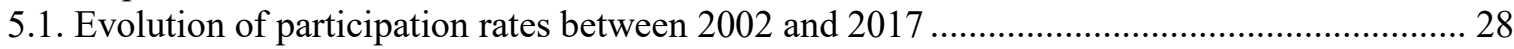

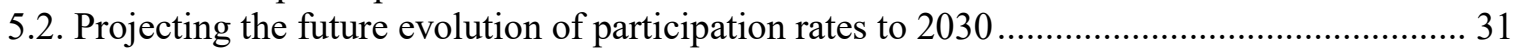

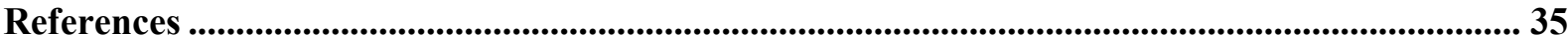

Annex A. Individual country charts for participation rates................................................................... 37

Annex B. Description and source of variables .........................................................................39

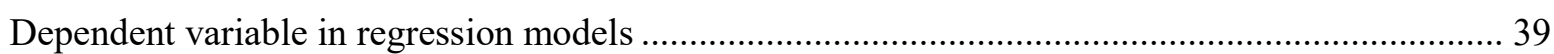

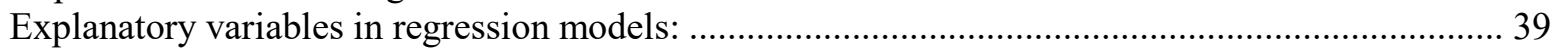

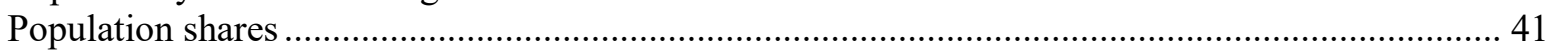

Annex C. Individual country charts for pension wealth .............................................................................. 42

Tables

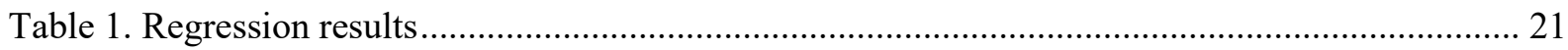

Figures

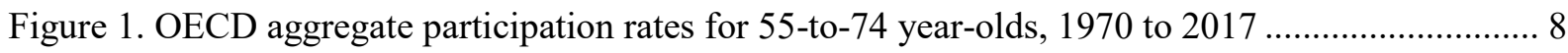

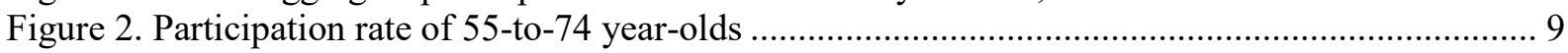

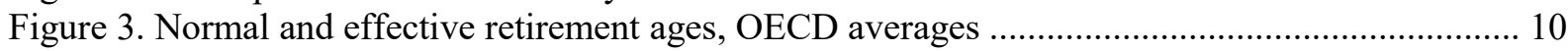

Figure 4. Participants in early retirement programmes in selected OECD countries ........................... 10

Figure 5. The older-age participation response following the early 1990s downturn and the GFC...... 11

Figure 6. Change in normal retirement age relative to life expectancy at 65 .................................... 13

Figure 7. Replacement rate and pension wealth from mandatory pension schemes in France in 201714

Figure 8. Occupational pension plans of Fortune 500 companies in the United States by type........... 16

Figure 9. Illustrative age profile of conditional participation rates before and after one-year increase

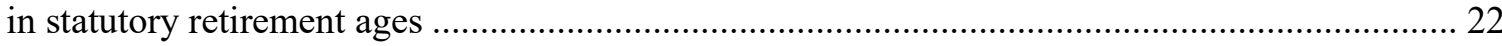


Figure 10. Impact on participation rate of 55-to-74 year-olds of raising minimum and normal retirement ages by one year in 2017, taking account of implied change in pension wealth.......... 22

Figure 11. Estimated differences in participation rates relative to 55 year-old men ............................ 25

Figure 12. Estimated differences in participation rates relative to men with low education................. 26

Figure 13. Cross-country heterogeneity in the impact of statutory retirement ages ............................. 27

Figure 14. Cross-country heterogeneity in the impact of pension wealth ........................................... 28

Figure 15. Decomposition of change in participation rate of 55 -to-74 year-olds ............................... 30

Figure 16. Projected change in participation rates of 55-to-74 year-olds between 2017 and 2030

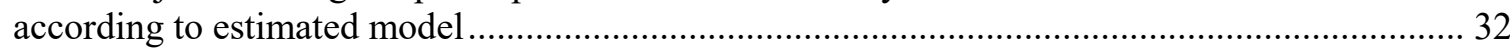

Figure 17. Impact of change in old-age participation on real GDP per capita by 2030 ...................... 33

Figure 18. Additional increase in participation rate of 55-to-74 year-olds if minimum and normal retirement ages rise by at least two-thirds of gains in life expectancy at 65 .............................. 34 


\section{Main findings}

- After decades of decline, there has been a remarkable turnaround in the participation rate of older people in almost all OECD countries since the turn of the century. Various strands of evidence suggest that the tightening of alternative early retirement pathways through unemployment and disability schemes has been a major factor in this turnaround.

- This paper examines the past and possible future contributions of changes to mandatory pension schemes, and in particular statutory retirement ages, to labour market participation of 55-to-74 year-olds using new measures of financial incentives in mandatory pension schemes for 26 OECD countries, a sample period extending to 2017 and participation rates by single years of age, sex and education.

- According to estimated equations that impose homogenous cross-country coefficients on pension system parameters, raising both the minimum and normal retirement ages by one year increases the participation rate of 55 -to- 74 year-olds by $3 / 4$ percentage points in the median country, in line with previous studies. An alternative specification allowing for country-specific coefficients shows significant heterogeneity, suggesting that the effects of pension reforms on labour supply could be more than twice the median effect in some countries.

- Reduced sensitivity of old-age participation to the level of unemployment, dramatically illustrated by the different response following the Global Financial Crisis and the downturn of the early 1990s, suggests that the early retirement pathways available through unemployment programmes have narrowed.

- A decomposition of changes to participation rates of 55-to-74 year-olds between 2002 and 2017 attributes more than two thirds of the median increase of 10.9 percentage points to rising life expectancy and educational attainment. About 1 percentage point is attributable to changes in statutory retirement ages, although part of the reason this median effect is small is that in most countries, statutory retirement ages have not kept pace with life expectancy.

- Projections indicate that participation rates for 55-to-74 year-olds should keep rising through 2030, by 3.4 percentage points for the median country. Rising life expectancy and educational attainment are projected to make the largest contributions, more than compensating for the negative contribution of population ageing in most countries.

- If age-specific participation rates remained stable at current levels, ageing populations would lower GDP per capita in the median OECD country by $5 \frac{1 / 2}{2}$ per cent by 2030 . Relative to this artificial baseline, projected increases in old-age participation rates offset some, but not all of these losses, 3 percentage points in the median country, but as much as 5-6 percentage points in Spain, Greece and Italy if current unemployment gaps close as assumed.

- In countries that are not planning any future increase in statutory retirement ages, raising them by two thirds of the projected increase in life expectancy could add up to 1.4 percentage points to the participation rate of 55-to-74 year-olds by 2030 . 


\title{
Labour supply of older people in advanced economies: the impact of changes to statutory retirement ages
}

\author{
by Christian Geppert, Yvan Guillemette, Hermes Morgavi and David Turner ${ }^{1}$
}

\section{Introduction}

1. Age-specific participation rates tend to decline from middle age onwards. Consequently, population ageing is projected to push down aggregate participation rates in OECD countries in the decades ahead. Slower working-age population growth and rising dependency ratios are projected to weigh on the progress of living standards in almost all OECD countries through 2060 (Guillemette and Turner, 2018 $[1]$ ). In addition, these demographic trends will simultaneously put downward pressure on government revenue and upward pressure on spending, in particular pension and health-related expenditure.

2. Encouragingly, after declining for decades, participation rates for 55-to-74 yearolds began rising at the turn of the century in almost all OECD countries. Were this trend to continue, it could offset some of the negative pressure that population ageing will otherwise apply to living standards. Understanding the reasons behind the uptrend in participation rates at older ages, and especially the contribution of public policies, is therefore important to inform policymaking going forward. This paper examines the contribution of reforms to mandatory pension schemes, in particular changes to statutory retirement ages, to the recent evolution of participation rates for 55-to-74 year-olds in 24 European OECD economies as well as the United States, Canada and Japan.

3. Previous studies and country-specific experiences point to a general policy shift during the 1990s and early 2000s in many OECD countries, away from favouring early retirement. This shift took the form of a gradual closing of early retirement pathways available via unemployment and disability programmes, which allowed workers to bridge the gap between an early end to their careers and normal social security benefits. There is little doubt that this policy shift is a major factor behind the turnaround from declining to rising participation rates of older people. But now that they have largely been closed, early retirement pathways cannot be closed a second time. Policy discussions today have thus mainly turned to the option of raising statutory retirement ages. Many governments have done so already and some have legislated future increases. In this context, the objectives of this paper are to quantify the contribution of recent changes to statutory retirement ages to the rise of participation rates for older people since 2002 and illustrate how much they could contribute in the future.

\footnotetext{
${ }^{1}$ The authors are with the Directorate for Employment, Labour and Social Affairs (Geppert) and the Economics Department (Guillemette, Morgavi and Turner) of the OECD. They would like to thank Sebastian Barnes, Hansjoerg Bloechliger, Sven Blondäl, Laurence Boone, Hervé Boulhol, Aida Caldera Sanchez, Luiz De Mello, Alain De Serres, Mikkel Hermansen, Jens-Christian Hoj, Yehuda Porath, and participants to the March 2019 Working Party 1 meeting of the OECD Economic Policy Committee, for comments and suggestions on earlier drafts of the paper; as well as Veronica Humi for preparing the document for publication.
} 


\section{Participation rates of 55-to-74 year-olds}

4. The evolution of participation rates for 55-to-74 year-olds in the OECD shows a striking reversal around the turn of the century. From the early 1970s to 2002, the aggregate participation rate for this age group declined steadily (Figure 1, Annex A). From 2002 to 2017, however, it rose by 9 percentage points. The long trend decline to 2002 was significantly more pronounced for men than women, while the uptrend since 2002 is somewhat stronger in the case of women.

Figure 1. OECD aggregate participation rates for 55-to-74 year-olds, 1970 to 2017

Per cent of population aged 55 to 74

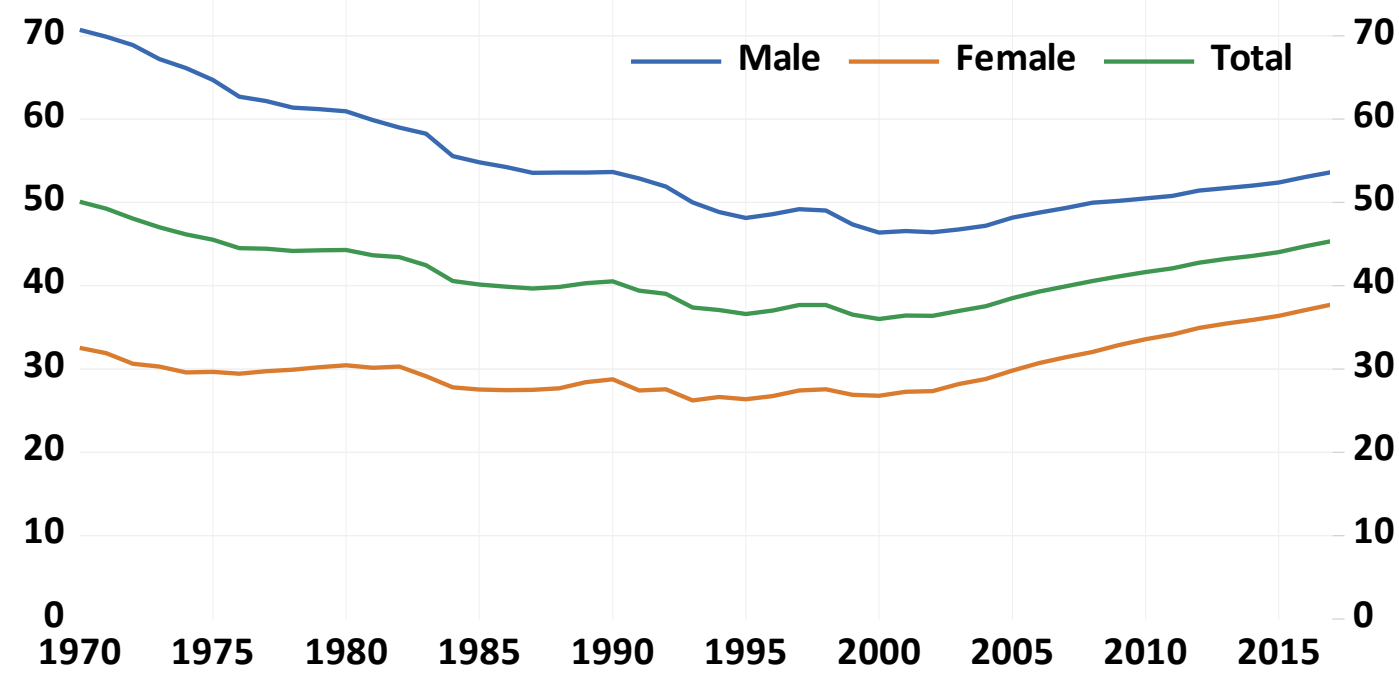

Note: The aggregates are obtained by summing labour force in the 55-to-74 age group over the available countries and 5-year age groups and dividing by population. The coverage of countries and age groups in these aggregates increases over time. Narrower aggregates with constant coverage, as well as unweighted averages (arithmetic means) reveal the same general storyline, except that the trend increase in participation may have started somewhat sooner.

Source: OECD labour force statistics and authors' calculations.

5. The trend increase in participation since the beginning of the 2000s has been broad based across OECD countries, although magnitudes vary a lot (Figure 2). Only Iceland and Turkey have bucked the trend, the first because it already had very high participation in 2002 , and the second due to falling participation among women but not men. There are also important differences in the level of participation rates for 55-to-74 year-olds across OECD countries (Figure 2). Countries outside Europe, in particular Australia, Japan, Korea and New Zealand, tend to have higher participation rates than European countries. Across countries, participation rates of men and women in this age range are highly positively correlated, so there is no tendency for high total participation rates to be explained only by high female participation. However, this paper focuses on explaining changes in participation rates between 2002 and 2017, rather than level differences across countries. 
Figure 2. Participation rate of 55-to-74 year-olds

A. Males, per cent of population aged 55 to 74

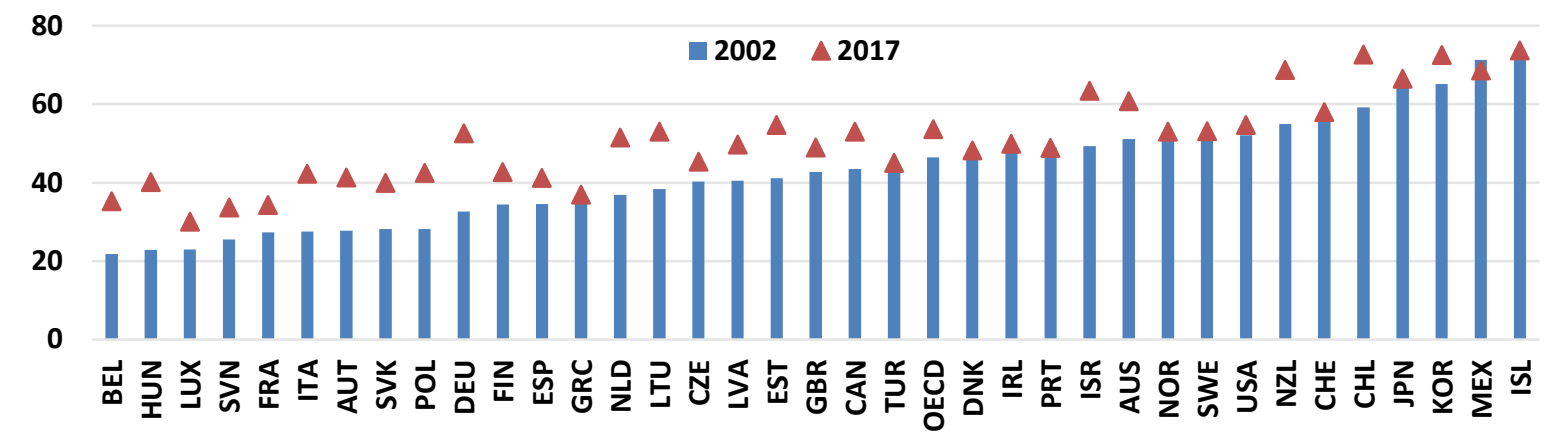

B. Females, per cent of population aged 55 to 74

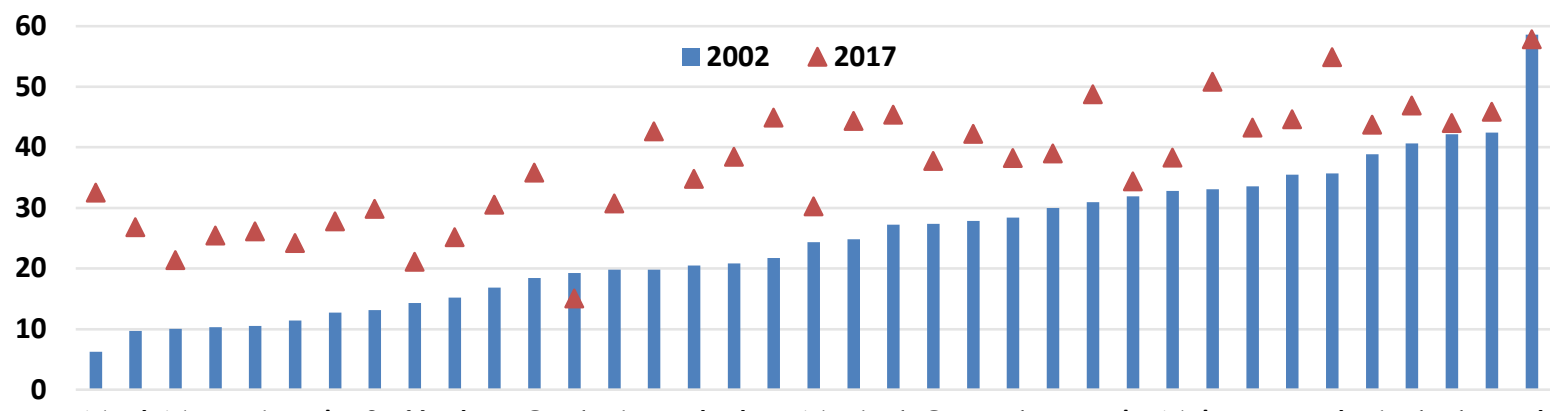

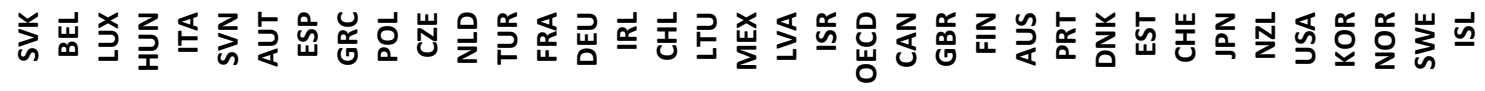

Source: OECD labour force statistics and authors' calculations.

\section{Drivers of participation rates for older people and results from previous studies}

\subsection{Potential drivers of change to participation rates of 55-to-74 year-olds}

\subsubsection{Retirement incentives in mandatory pension and social security systems}

6. Incentives embedded in mandatory pension and social security programmes are crucial determinants of labour supply decisions at older ages (Coile, Milligan and Wise, $\left.2018_{[2]}\right)$. Many governments used to favour early retirement, to make way for the young and reduce youth unemployment. The policy bias is visible in declining normal retirement ages, defined as the qualifying age to receive a full pension, through the 1970s, 1980s and early 1990s (Figure 3). Governments also used to favour early retirement via unemployment or disability programmes, whose benefits could often be used to bridge the gap to the minimum statutory retirement age. This policy bias is reflected in the faster decline of effective versus normal retirement ages, or in other words in declining wedges between effective and statutory ages (Figure 3). In response to rising pressure on public finances from ageing populations, many countries have reformed retirement schemes and closed down early retirement pathways to encourage longer working lives. The change of view that occurred around the mid-1990s - notably involving a shift of emphasis from compensation to integration in sickness and disability policies across many OECD countries $\left(\mathrm{OECD}, 2010_{[3]}\right)$ - coincides with the flattening of effective retirement ages followed by the beginning of the uptrend (Figure 3). Since then, the share of 55-to-64 
year-olds receiving early retirement benefits has been falling, along with public expenditure on these programmes (Figure 4).

Figure 3. Normal and effective retirement ages, OECD averages
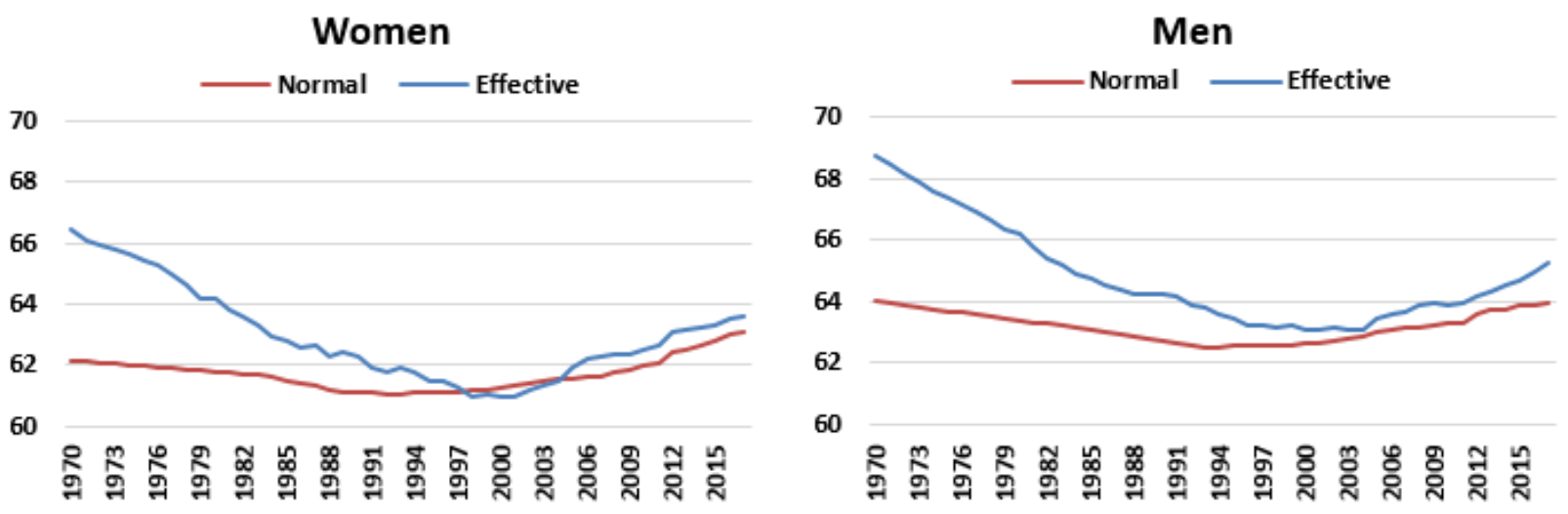

Note: Normal retirement age is based on labour market entry at age 20 and a full career.

Source: OECD (2017), Pensions at a Glance 2017: OECD and G20 indicators, OECD Publishing, Paris; and information provided by member countries.

Figure 4. Participants in early retirement programmes in selected OECD countries

Per cent of population aged 55 to 64

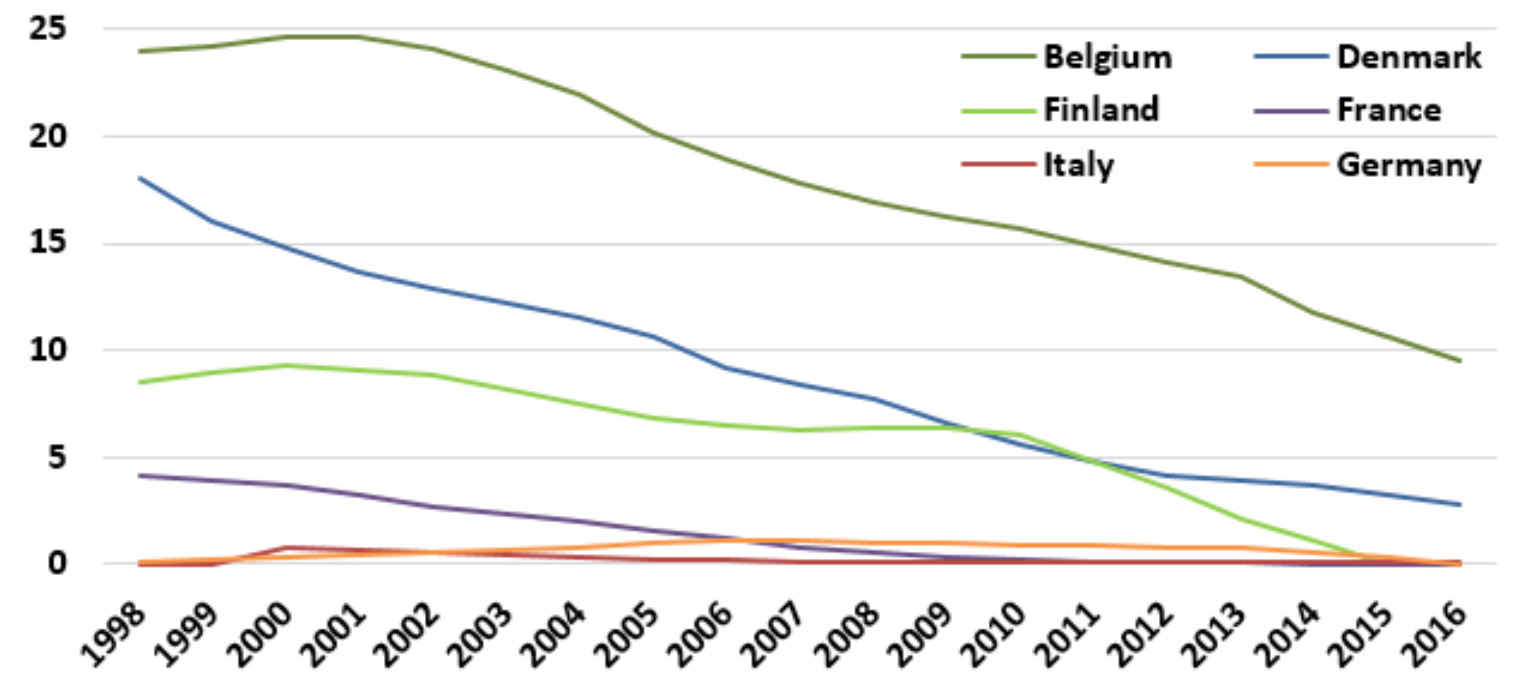

Note: The countries selected are those with long time series. Early retirement programmes are defined as those facilitating full or partial early retirement of older workers who are assumed to have little chance of finding a job or whose retirement facilitates the placement of an unemployed person or a person from another target group. Early retirement benefits normally cease when the beneficiary becomes entitled to an old age pension. Source: OECD Labour Market Programmes database and Labour Force Statistics. 
7. The tightening of early retirement pathways is also illustrated by the different response of older-age cohorts to the Global Financial Crisis than to the generalised downturn that took place in the early 1990s. ${ }^{2}$ Following the downturn of the early 1990s, the participation rate of older cohorts fell in practically all OECD countries. On average, each percentage point rise in the aggregate unemployment rate was accompanied by a fall in the participation rate of older cohorts by just under one percentage point, but with many countries experiencing a much larger fall (Figure 5, Panel A). Conversely, following the Global Financial Crisis, most OECD countries did not experience any fall in the older age participation rate and, for those that did, the magnitude of the fall was modest compared to the experience of the early 1990s downturn (Figure 5, Panel B).

Figure 5. The older-age participation response following the early 1990s downturn and the GFC

Peak fall in the participation of age group 55-64 as percentage of the peak rise in the unemployment rate

A. Following the downturn of the early 1990 s

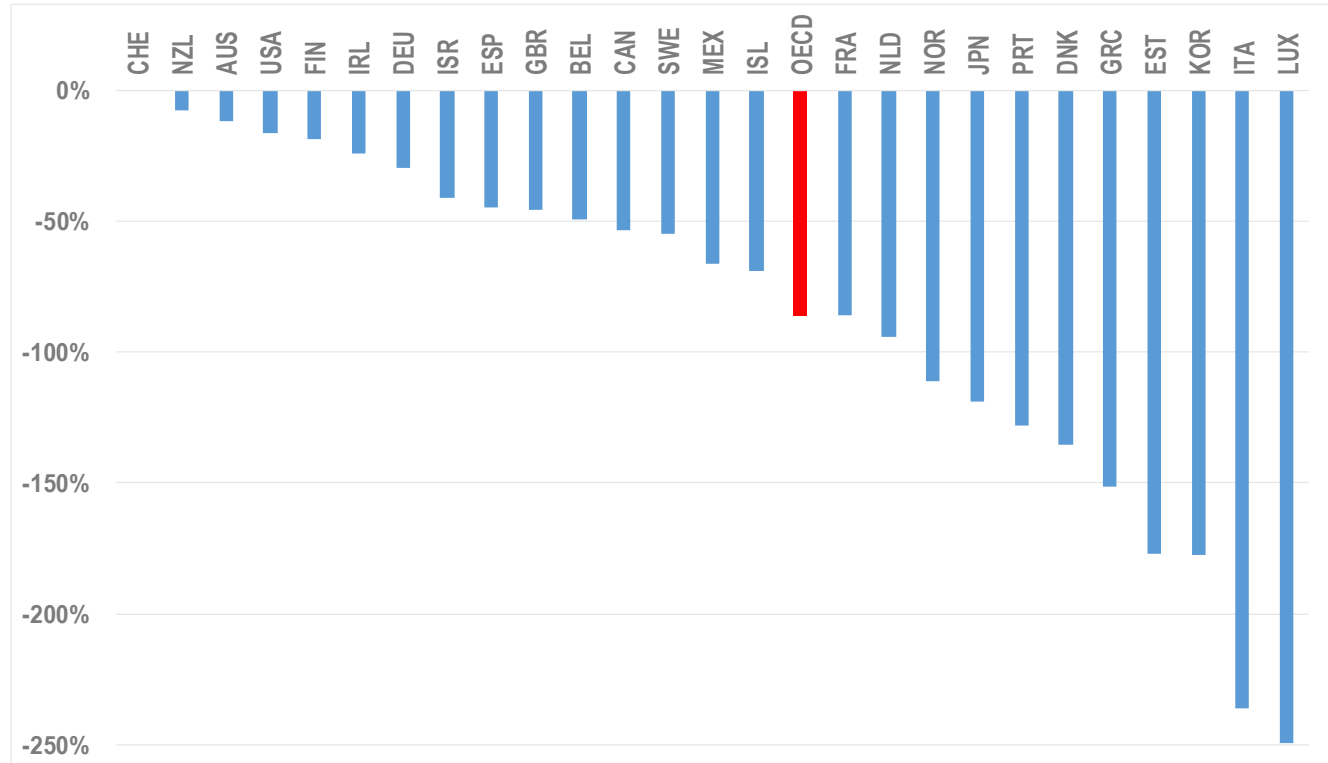

\footnotetext{
${ }^{2}$ Figure 5 relies on participation rates for 55-to-64 year-olds rather than 55-to-74 year-olds as in the rest of the paper because the broader definition is unavailable for many countries when going back to the early 1990s.
} 
Figure 5. The older-age participation response following the early 1990s downturn and the GFC (contd.)

B. Following the Global Financial Crisis

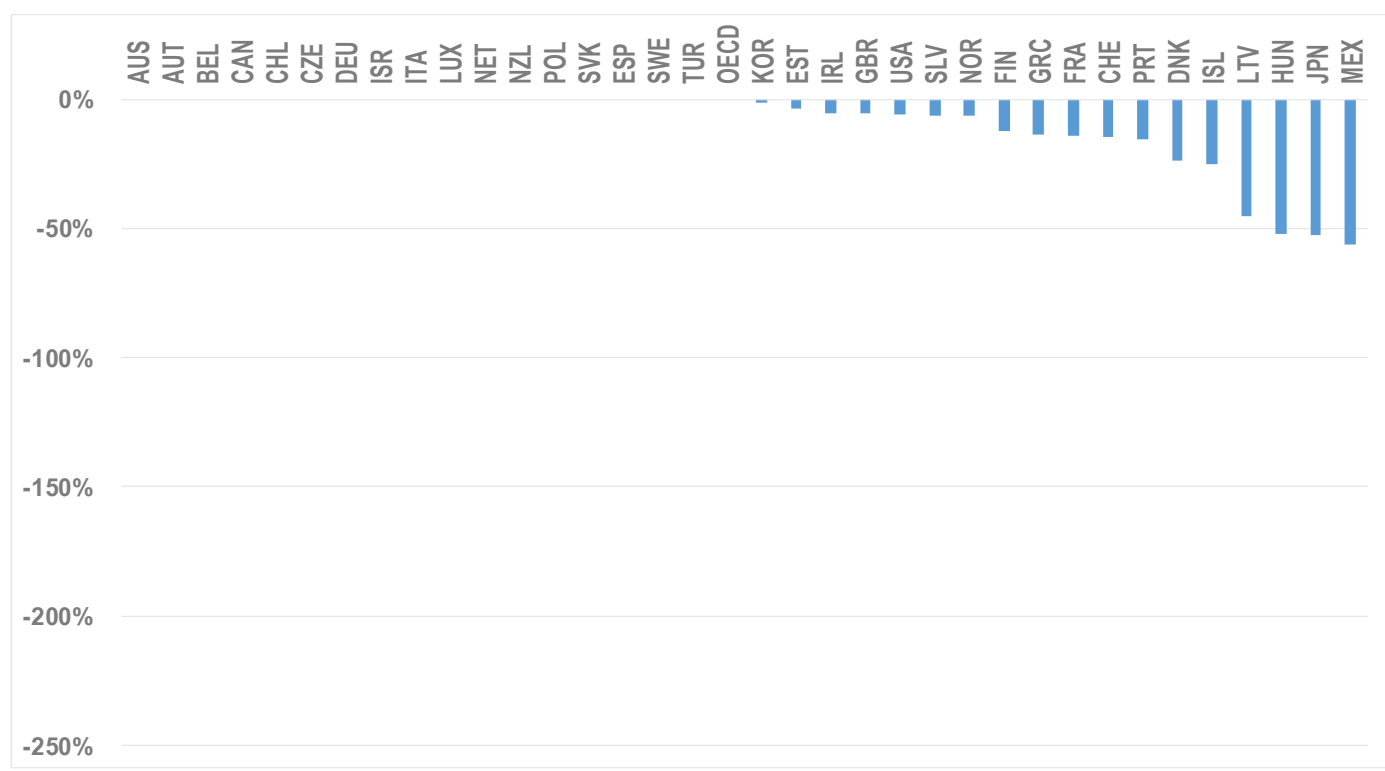

Note: The charts compare the maximum fall in the participation rate of 55-to-64 year-olds normalised on the peak rise in the aggregate unemployment rate in the five years following the downturn that occurred at the beginning of the 1990s (in Panel A), and in the five years following the Global Financial Crisis (Panel B). Hence, a figure of $-200 \%$ implies that the maximum percentage point fall in the elderly participation rate was double the percentage point peak rise in the aggregate unemployment rate over that period. A figure of zero implies that there was no fall in the elderly participation rate in the 5 years following the downturn. To emphasise the comparison between the two periods, the two panels use the same scale.

8. Many OECD governments have also been tightening standard retirement pathways. Over the last two decades, almost all OECD countries have increased their normal retirement age (Figure 3). In the case of men, increases since 2002 have generally not kept pace with rising life expectancy, the only exceptions being Latvia, Greece, Slovenia as well as Japan, which started from a comparatively low level (Figure 6). For women, retirement ages have increased by more, reflecting the trend toward standardised retirement ages. Minimum retirement ages, defined as the eligibility ages for a (possibly reduced) pension, underwent similar changes. 
Figure 6. Change in normal retirement age relative to life expectancy at 65

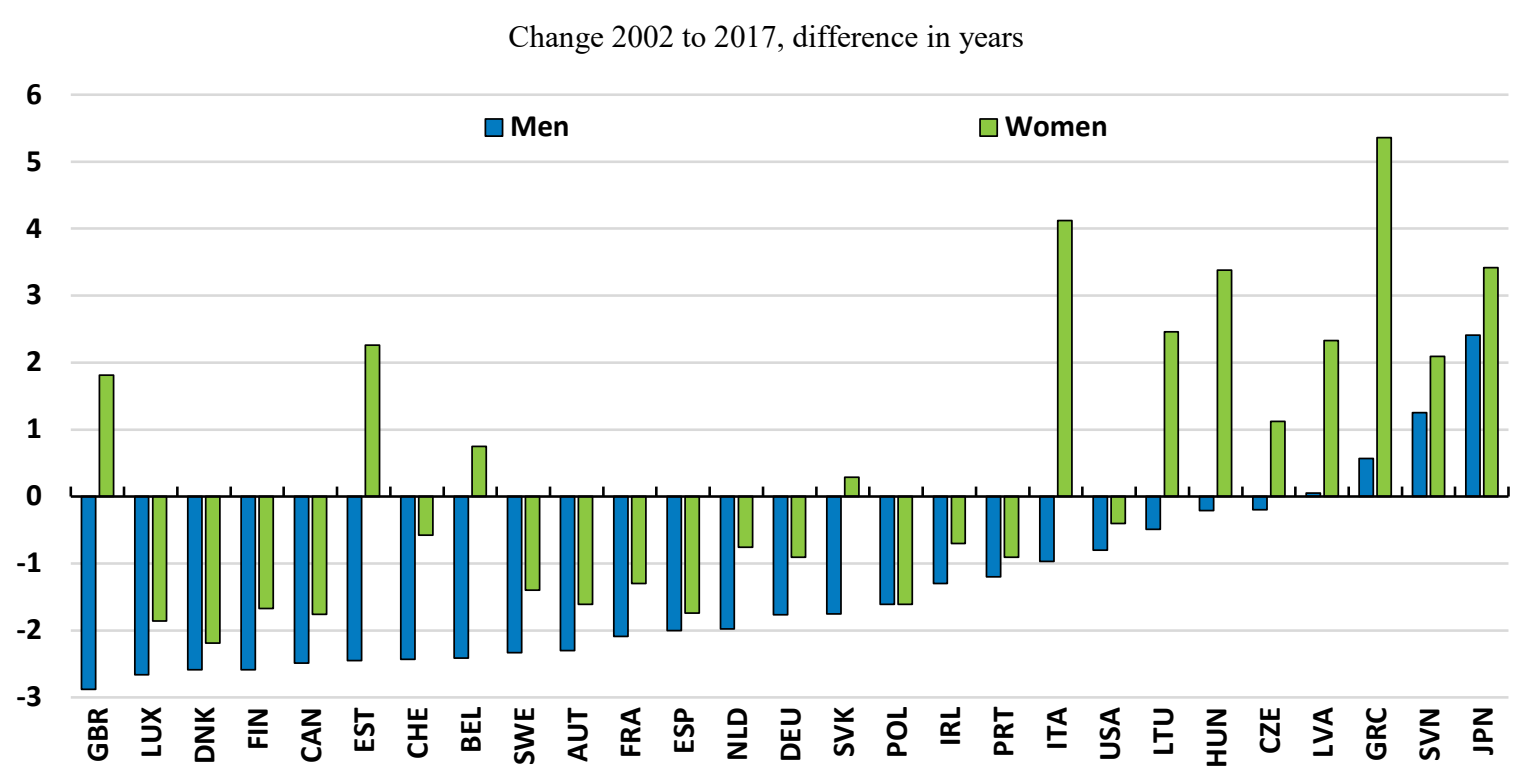

Note: Each bar shows the difference between the increase in the normal retirement age and the increase in life expectancy at age 65 over the period 2002 to 2017 for a given country and sex. A negative value implies that the normal retirement age has not kept pace with the increase in life expectancy. The normal retirement age is defined for a worker with a full career after entering the labour market at age 25 (see Appendix B).

Source: Authors' calculations based on information in US Social Security Administration (2002-2018), Social Security Programs Throughout the World; MISSOC database (2017), Comparative Tables; OECD (2017), Pensions at a Glance: OECD and G20 indicators; and UN (2017), World Population Prospects: The 2017 Revision.

9. Besides eligibility ages, mandatory pension schemes influence the labour supply decision through the benefit level and how it varies with the timing of retirement (BörschSupan and Coile, 2018 $\left.8_{[4]}\right)$. These financial incentives result from the overall design of a pension system and can be summarised using various related concepts. Two such concepts are the rate of earnings replacement upon withdrawal from the labour market ("replacement rate") and the net present value of the expected pension stream over the retirement spell ("pension wealth") (see Annex B for definitions).

10. Taking an average earner in the 2017 French pension system as an example (see Annex C for other countries' pension wealth profiles), the replacement rate of zero before age 62 indicates that a worker who entered the labour market at age 25 and with a full career cannot receive a pension before age 62 (Figure 7, Panel A). Retiring at 62 would give rise to a gross pension replacing about $50 \%$ of earnings, for both women and men. Each year of postponed retirement would yield additional percentage points of replacement, up to a replacement rate of more than $80 \%$ if the worker remained employed until age 75 . 
Figure 7. Replacement rate and pension wealth from mandatory pension schemes in France in 2017

A. Replacement rate

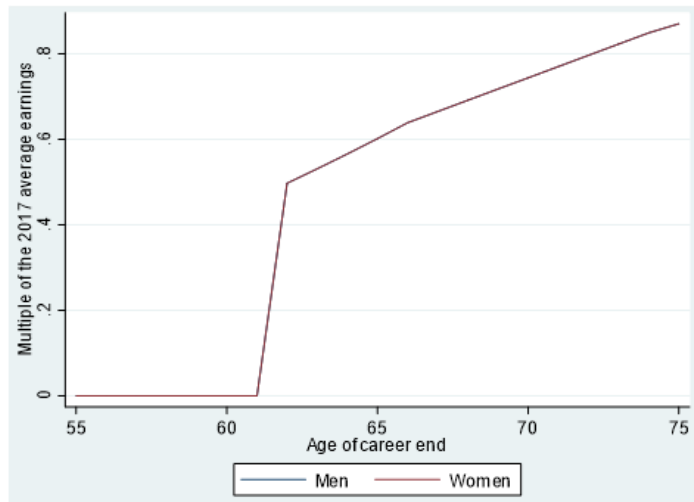

B. Pension wealth

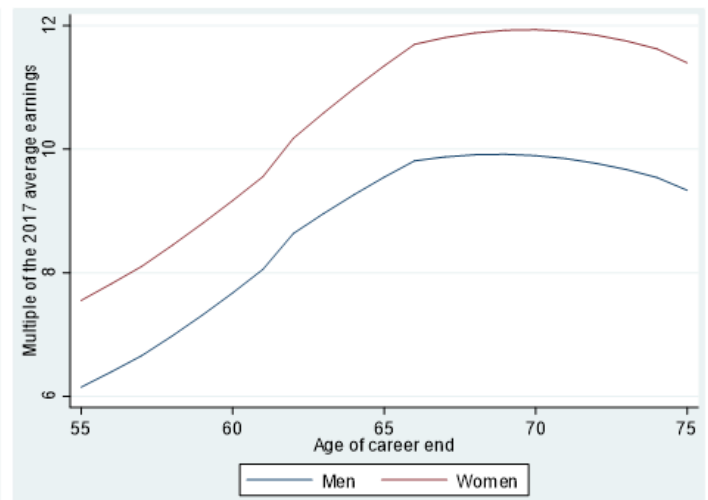

Note: The calculations apply to a worker with average earnings over a full career after entering the labour market at age 25 and includes old-age pensions from the main scheme but ignoring phased retirement, which allows a gradual labour market exit from age 60 . The charts show a cross-section of estimates for a given year rather than a life cycle profile for a specific cohort, but the former is a close approximation to the latter. See Annex C for pension wealth profiles of other countries.

Source: Authors' calculations based on information in US Social Security Administration (2002-2018), Social Security Programs Throughout the World; MISSOC database (2017), Comparative Tables; OECD (2017), Pensions at a Glance: OECD and G20 indicators; and UN (2017), World Population Prospects: The 2017 Revision.

11. Pension wealth results, broadly speaking, from the product of the replacement rate and expected remaining lifetime at career end, accounting for indexation of the pension payment. The difference in pension wealth between two consecutive age groups is closely related to the concept of the implicit tax on continued work (Blöndal and Scarpetta (1999 $\left.{ }_{[5]}\right)$; Duval $\left(2004_{[6]}\right)$ and others) which measures the loss of lifetime pension income in case retirement is delayed. Pension wealth rises quickly at younger ages because in the event of an early career end, a waiting period would apply until the first pension payment, creating an incentive to postpone retirement (Figure 7, Panel B). Conversely, at older ages, pension wealth tends to decline as a shorter expected length of pension receipt overcomes the effect of a higher replacement rate in case of later retirement. Even if pension policies apply identically to men and women, as in France, women's pension wealth exceeds that of men at all ages for the same career because of higher life expectancy.

\subsubsection{Population ageing}

12. Because participation rates differ across age groups, changes to the age structure of the population can affect the evolution of the aggregate labour market participation rate. In recent years, population ageing has generally been pushing up the proportion of people aged 55 to 74 in the total population of OECD countries. Within the 55-to-74 age group, however, the impact of demography depends on the country and the exact period considered. In many countries, the proportion of 55-to-59 year-olds increased rapidly in the early 2000s as the baby-boom generation reached this age range, and fell thereafter as the generation progressed in age. Lately, the proportion of 70-to-74 year-olds has been rising in many countries. These are generalisations, however, and the evolution of population shares within the 55-to-74 age range differs importantly across countries. 


\subsubsection{Rising educational attainment}

13. Labour force participation tends to increase along with educational attainment. Empirical evidence of this pattern comes from cohort-based analyses of labour market participation, which capture the changing educational composition of the population through fixed cohort effects (e.g. Fallick and Pingle (2007 $[7]$ ); Balleer, Gómez-Salvador and Turunen $\left(2009_{[8]}\right)$; Grigoli, Koczan and Tapalova $\left(2018_{[9]}\right)$ ). Educational attainment has risen particularly strongly among women, contributing to the increase in the female labour force participation rate.

\subsubsection{Better health}

14. Micro-level literature points to clear positive effects of health on employment and to these effects strengthening with age (Kalwij and Vermeulen, 2008 ${ }_{[10]}$; Currie and Madrian, $\left.1999_{[11]}\right)$. The advantage of micro-level studies is that they rely on direct measures of work-related health conditions, such as people's limitations on daily self-care activities (ADLs), or self-reported health measures, which may however suffer from self-reporting bias. Direct indicators of population-wide health relevant for work capacity, like disabilityfree ("healthy") remaining life expectancy at age 65, are unavailable over a long period for many countries. Hence, macro-level studies often approximate changes in public health with the evolution of mortality rates or life expectancy. Besides the direct effect of better health on the capacity to work, higher life expectancy may also boost employment via the need for higher lifetime income.

\subsubsection{Changing nature of work}

15. Poor and unsuitable working environments may be detrimental to workers' physical and mental health $\left(\right.$ OECD, 2014 $\left.{ }_{[12]}\right)$. Working conditions are often ill suited to the needs and capacities of older people and can have an important bearing on older workers' decisions to keep working or retire. Deindustrialisation and the rise of new technologies, in particular the digital economy, are changing the nature of work. Less physically demanding, less polluted and therefore healthier workplaces provide older workers with the possibility of remaining longer in the labour market. According to the 2015 European Surveys on Working Conditions, 38\% of older workers in the EU28 were exposed to physically unpleasant conditions at least half of the time, a reduction of 5 percentage points relative to 2005. At the same time, new technologies can eliminate jobs via automation, thereby challenging the future of work, in particular for low-skill occupations and possibly lowering aggregate labour market participation $\left(\mathrm{OECD}, 2018_{[13]}\right.$; Grigoli, Koczan and Tapalova, 2018[14]).

\subsubsection{Rising female labour force participation}

16. While female labour force participation remains below that of men, younger generations of women are gradually narrowing the gap. This phenomenon needs, however, to be related to other, more fundamental, factors. Among those are factors already cited such as rising educational attainment among women (c.f. 3.1.3), the expansion of the services sector and of part-time employment (c.f. 3.1.5), to which can be added changing social norms, such as greater acceptance of non-parental childcare, which have led to lower and delayed fertility. Policy changes have also contributed to the trend, notably the expansion of formal childcare services for children below three, especially in countries with relatively high employment protection (Thévenon, 2013 $3_{[15]}$ ). 


\subsubsection{Increasing but more concentrated private wealth}

17. Economic growth of past decades has boosted average wealth levels but has also pushed up wealth inequality in OECD countries, with no or even negative wealth growth in some parts of the population (Piketty, $\left.2014_{[16]}\right)$. Higher wealth makes early retirement more affordable and, as a normal good, leisure time tends to rise with income or wealth. However, at least for the United States, labour supply differs rather little across the wealth distribution (Chang and Kim, 2007 ${ }_{[17]}$ ). Perhaps government transfers, capital income taxation and other factors offset some of the effects of wealth concentration (Yum, $\left.2018_{[18]}\right)$.

18. Occupational and supplementary pension contracts are crucial components of private wealth and particularly relevant to the retirement decision. Within the private sector, many firms have, or are in the process of, winding down their defined-benefit (DB) plans in favour of defined-contribution (DC) arrangements, particularly in Anglo-Saxon countries like the United States (Figure 8). This change usually involves lowering benefit levels and shifting investment, inflation and longevity risk from the employer to the employee, thereby creating additional incentives to work longer (OECD, 2018 $\left.{ }_{[19]}\right)$.

Figure 8. Occupational pension plans of Fortune 500 companies in the United States by type

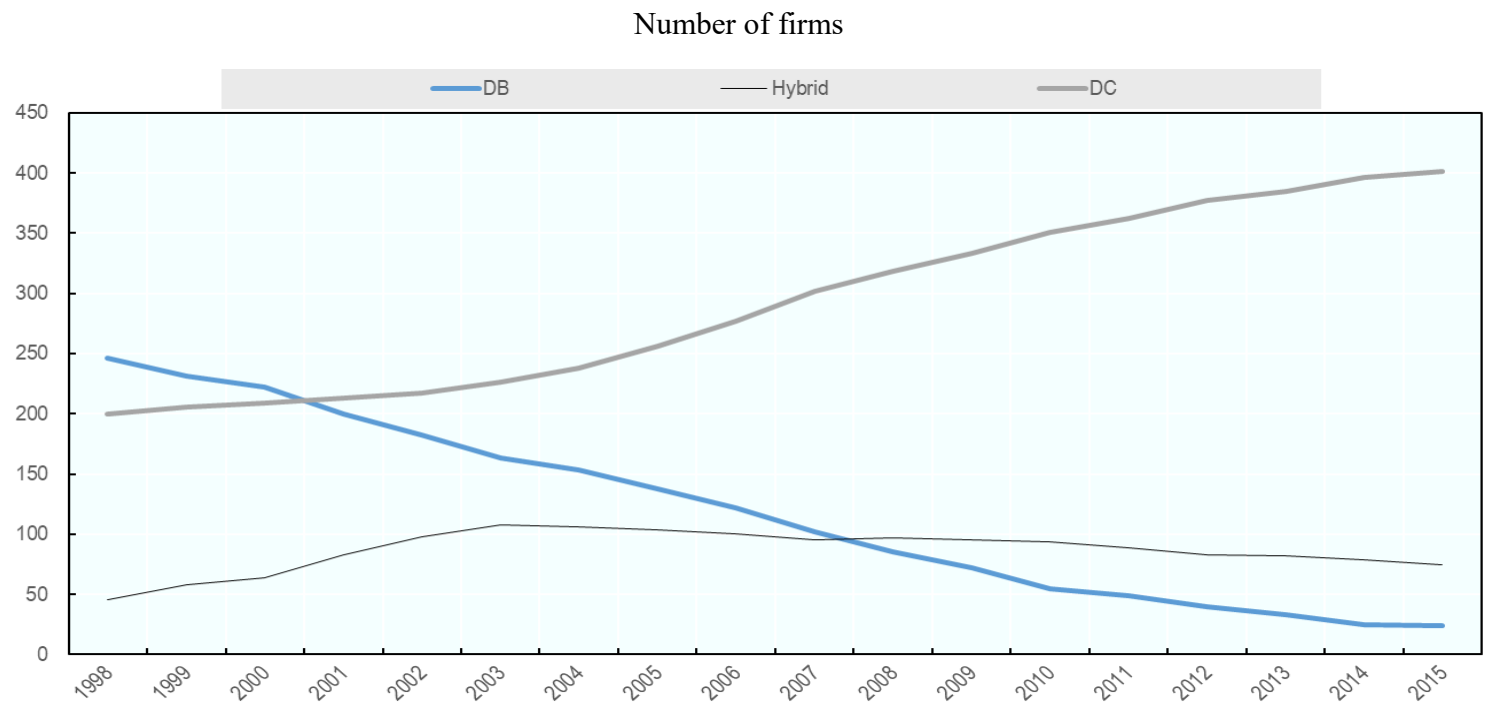

Source: McFarland, B. (2016), "A continuing shift in retirement offering in the Fortune 500 companies", Insider, Vol. 26, No. 2, Willis Towers Watson.

\subsubsection{Business cycle}

19. Generally, the aggregate participation rate tends to decline when the economy is depressed and rise when it is booming, lagging the business cycle somewhat. Discouraged workers who withdraw from the labour market in economic downturns tend not to return in full numbers in subsequent booms, with women affected more than men and the old more than the young given that labour market exit in old age tends to be permanent (Darby, Hart and Vecchi, 2001 $[20])$. Among the old, this 'discouraged worker effect' was much less apparent following the great recession of 2009 than following severe downturns during the 1980s and 1990s (Figure 5), probably because early retirement pathways through disability or unemployment benefits were less easily available. However, extremely depressed 
economic conditions may affect participation positively via other channels. For instance, a decline in the value of savings may force some people to keep working longer than anticipated to rebuild savings.

\subsection{Disentangling the contribution of the potential drivers to the recent uptrend in participation at older ages}

20. Among recent cross-country studies that specifically examine participation or employment rates at older ages, the present study is closest in aim and methods to Blöndal and Scarpetta (1999 $\left.{ }_{[5]}\right)$, Duval $\left(2004_{[6]}\right)$, Gal and Theising $\left(2015_{[21]}\right)$, Grigoli, Koczan and Tapalova $\left(2018_{[14]}\right)$, as well as the various phases of an ongoing project on Social Security Programs and Retirement Around the World ${ }^{3}$ (Box 1). The earlier studies emphasise the powerful influence of financial incentives associated with social security programmes on late-career labour supply decisions. By contrast, the latest studies tend to find that policies have played a small role in explaining the uptrend in participation rates since the turn of the century relative to other factors, such as rising educational attainment and technological change. These two views can, however, be reconciled by noting the different sample periods on which different studies focus: there is strong evidence that alternative early retirement pathways were more important in the 1980s and 1990s and so featured strongly in studies focused on that period. Conversely, more recent studies, such as the present, focus mostly on the post-2000 period.

Box 1. Selected results on drivers of employment/participation of older people from previous studies

This box highlights results from the papers mentioned in the main text that are relevant to the labour supply of older people:

- Blöndal and Scarpetta $\left(1999_{[5]}\right)$ found that more generous early retirement benefits and a higher unemployment rate were both associated with lower participation for 55-to-64 males over the 1971-to-1995 period. They also reported that in many countries, a large share of 55-to-64 yearold males were receiving invalidity pensions in 1990. These findings suggest that during the period until the mid-1990s, many governments were encouraging older workers to retire early via unemployment and disability schemes.

- Duval $\left(2004_{[6]}\right)$ found that changes to retirement incentives in social security programmes (implicit tax rates on continued work and standard retirement ages) explained only about a third of the trend decline in males' labour force participation rates over the three decades to 1999. Nevertheless, he observed that the potential impact of policy reforms on labour force participation was fairly large given the magnitude of retirement incentives still embedded in pension schemes and other social transfer programmes.

- Gal and Theising $\left(2015_{[21]}\right)$ do not use indicators of financial incentives in social security system in their framework, focusing instead on broader labour market policies. They find a positive effect on the employment rate of older people from active labour market policies and the statutory retirement age and negative effects from the unemployment insurance benefit replacement rate and tax wedges.

- The project on Social Security Programs and Retirement Around the World, for instance Gruber and Wise $\left(1999_{[22]}\right)$, showed that in the mid-1990s, financial incentives to work at older ages varied dramatically across countries and were strongly related to employment. The project's

${ }^{3}$ See Coile, Milligan and Wise $\left(2018_{[2]}\right)$ for an overview and a list of earlier references. 
latest results, recent enough to consider the turnaround in trend participation at older ages, suggest that changes in health, education and the labour supply behaviour of married couples are insufficient to explain the magnitude of the increase in participation and its large variation across countries (Börsch-Supan and Coile, 2018 $8_{[4]}$ ).

- Grigoli, Koczan and Tapalova $\left(2018_{[14]}\right)$ found that policies made only a small contribution to the general upward trend in participation rates, at least up to 2011. Policies accounted for only around 2 percentage points of the nearly 8-percentage point increase in the participation rate of people aged 55+ in advanced countries over the 1995-to-2011 period. Instead, the upward trend stemmed mostly from rising educational attainment (contribution of around 4 percentage points), as well as structural factors - rising service-sector employment and urbanisation - with technological progress and rising trade openness contributing negatively.

\section{Impact of policy indicators on participation/employment rate of older people in selected cross-country studies}

Impacts of one-unit change in explanatory variable on participation/employment rate in percentage points

\begin{tabular}{|c|c|c|c|c|}
\hline & $\begin{array}{c}\text { Blöndal and } \\
\text { Scarpetta (1999) }\end{array}$ & Duval (2004) & $\begin{array}{l}\text { Gal and } \\
\text { Theising } \\
(2015)\end{array}$ & $\begin{array}{l}\text { Grigoli, Koczan } \\
\text { and Tapalova } \\
\text { (2018) }\end{array}$ \\
\hline Dependent variable & $\begin{array}{l}\text { Participation rate, } \\
\text { men } 55-64\end{array}$ & $\begin{array}{l}\text { Participation } \\
\text { rate, men } 55+\end{array}$ & $\begin{array}{l}\text { Employment } \\
\text { rate, } 55-64\end{array}$ & $\begin{array}{l}\text { Participation rate, } \\
55+\end{array}$ \\
\hline UE benefit replacement rate ( $\%$ of earnings) & & & -0.34 & \\
\hline Tax wedge (\% of labour costs) & & & -0.26 & -0.24 \\
\hline $\begin{array}{l}\text { Public spending on active labour market policies } \\
\text { (\% of GDP per capita per unemployed person) }\end{array}$ & & & 0.06 & -0.03 \\
\hline Union density ( $\%$ of wage earners) & & & & -0.12 \\
\hline Statutory retirement age & 0.8 to 1.0 & 0.7 & 0.85 & 0.66 \\
\hline Public spending on old-age pension (\% of GDP) & & & & -0.75 \\
\hline $\begin{array}{l}\text { Replacement rate for unemployment-related early- } \\
\text { retirement benefits (\% of earnings) }\end{array}$ & -0.15 to -0.2 & & & \\
\hline $\begin{array}{l}\text { Replacement rate for special early retirement } \\
\text { benefits (\% of earnings) }\end{array}$ & -0.03 to -0.05 & & & \\
\hline $\begin{array}{l}\text { Empirical framework also includes a } \\
\text { comprehensive measure of financial incentives in } \\
\text { social security programmes }\end{array}$ & Yes & Yes & No & No \\
\hline
\end{tabular}

21. A related important distinction between these studies lies in the set of policies considered in the empirical analysis and, in particular, the coverage of any measure of the financial incentives embedded in mandatory pension and social security systems. While the earlier studies tend to include comprehensive measures of these financial incentives, the latest studies focus instead on broader labour market policies and use only partial measures of social security system incentives, such as the statutory retirement age or total public spending on old-age pensions. While useful, such measures do not come close to capturing the full array of age, sex and career-specific financial incentives inherent in complex social security rules.

22. It is fair to say that it is not well understood at this point how much of the trend reversal in participation rates in OECD countries can be attributed to reforms of programmes that impact retirement directly, as opposed to broader structural trends like improving health and education, which are also influenced by policy. The above discussion makes clear that disentangling the potential explanations in an empirical framework requires an up-to-date measure of the financial incentives to retire produced by the social 
security system. The empirical analysis of the next section takes steps to fulfil this requirement and refines the methodologies of the recent studies cited above in several other ways. First, the data on participation rates are broken down by single years of age, which could a priori allow better identification of policy effects, in particular the influence of changes to statutory retirement ages, if participation drops suddenly at these ages. Second, participation rates are also broken down by sex and education levels, which allows controlling for these factors more finely than using aggregate explanatory variables. This could be important given differences in the life-cycle evolution of participation rates between sex and education groups. And third, the sample period extends to 2017, as opposed to 2010 in Gal and Theising $\left(2015_{[21]}\right)$ and 2011 in Grigoli, Koczan and Tapalova $\left(2018_{[14]}\right)$, thus capturing more of the recent uptrend in the participation rate of older people.

\section{Empirical analysis of single-age participation rates for older people}

\subsection{Empirical set-up and main results}

23. The dependent variable is the labour market participation rate, expressed as a percentage of the relevant population. It is broken down by sex, by single-age bracket going from 55 to 74 and by education level (low, medium and high). The data cover 26 countries, mostly in the EU, but also Switzerland, Canada and the United States (see Annex B for the list of countries and time coverage). ${ }^{4}$ The empirical strategy is to model the participation rate for country $i, \operatorname{sex} s$, age $a$, education level $e$ in year $t\left(P_{i, s, a, e, t}\right)$ using the following equation ${ }^{5}$ :

$$
P_{i, s, a, e, t}=\alpha_{i}+\gamma_{s}+\theta_{a}+\rho_{e}+\gamma_{s} \rho_{e}+\gamma_{s} \theta_{a}+\rho_{e} \theta_{a}+\sum_{j} \beta_{j} X_{i, s, a, e, t, j}+\varepsilon_{i, s, a, e, t}
$$

where $\alpha_{i}$ is a country fixed effect, $\gamma_{s}$ a sex fixed effect, $\theta_{a}$ an age fixed effect, $\rho_{e}$ an education fixed effect, $\gamma_{s} \rho_{e}$ a sex-education interaction effect, $\gamma_{s} \theta_{a}$ a sex-age interaction effect, $\rho_{e} \theta_{a}$ an education-age interaction effect, the $X_{j}$ are explanatory variables of interest and $\beta_{j}$ their associated coefficients and $\varepsilon$ is an error term. The sample period spans 1990 to 2017 but the panel is unbalanced (see Annex B for a description of variables, sources and country-specific time coverage).

24. Explanatory variables include direct policy drivers, secular trends that are also affected by policy, but with longer lags, and control variables:

- The direct policy drivers are statutory retirement ages (minimum and normal), as well as pension wealth or earnings replacement rate. The latter two capture policy-driven financial retirement incentives, but come short of being fully comprehensive. They consider only mandatory retirement pension systems (public or private) and not the full

\footnotetext{
${ }^{4}$ Japan is not included in the regression analyses because of constraints on obtaining the necessary data, but it is included in the decomposition analyses of the next section.

${ }^{5}$ Because participation rates lie between 0 and $100 \%$ by definition, a logit transformation of the dependent variable would be appropriate. In practice, however, most studies of participation rates use linear models. In addition, when using the logit transformation, results are very similar to those of the baseline specification. The mean absolute difference between the two approaches in predicted aggregate participation rates in 2017 is only 1.3 percentage points.
} 
array of social security programmes that may affect the retirement decision, notably unemployment insurance and disability schemes.

- Secular trends include life expectancy as well as the percentage of a population group with tertiary education. The latter variable is meant to capture the influence of educational attainment in the population beyond composition effects (for instance, if a more highly educated population also raises participation for the less educated via broader labour market effects). Public policies have of course a big influence on both health and education, but their effects on retirement decisions are indirect and come with long lags.

- The unemployment gap is included as a control variable, but as a 5-year moving average to account for the sluggish response of participation to cyclical developments. It is replaced by the unemployment rate in one specification.

Unfortunately, the empirical framework is missing an indicator of private wealth, a potentially important driver of labour supply (c.f. 3.1.7). ${ }^{6}$

25. Estimated coefficients from the baseline specification imply the following effects for the explanatory variables (Table 1, column 1):

- An increase in pension wealth equivalent to one year of earnings across the full 55-to74 age range lowers the participation rate of 55 -to- 74 year-olds by 0.8 percentage points. The effect has the expected sign but its magnitude seems small. However, it is likely that pension wealth is an important factor for some population groups and much less for others. Indeed, an alternative specification (not shown in the table) allowing for age and sex-specific coefficients on pension wealth reveals that this variable has the expected negative and statistically significant effect only for men aged 55 to 59 $(-1.1, p<0.10)$ and 60 to $64(-1.4, p<0.05)$. It makes intuitive sense that social security systems should have their strongest influence in the age range where most people retire and little influence past the typical age of retirement. It is surprising, however, to detect no influence on women's labour supply.

\footnotetext{
${ }^{6}$ Household net worth as a percentage of disposable income could conceptually serve as an indicator of private wealth, but the series available in National Accounts is not specific to the 55-to-74 age range, nor is it easily broken down by sex and education. Some household surveys contain useful wealth information at a micro level, but these are not very timely nor easily comparable across countries.
} 


\section{Table 1. Regression results}

Dependent variable: Participation rate by country, year, sex, education level and single year of age in age group 55 to 74

\begin{tabular}{|c|c|c|c|c|c|c|c|}
\hline & $(1)$ & (2) & $(3)$ & $(4)$ & $(5)$ & $(6)$ & $(7)$ \\
\hline Pension wealth (ratio to final earnings) & $-0.813^{*}$ & & $-0.813^{*}$ & $-0.847^{*}$ & $-0.762^{*}$ & $-1.461^{* * *}$ & $-0.822^{* *}$ \\
\hline Pension repl. rate (\% of final earnings) & & $-7.404^{* * *}$ & & & & & \\
\hline Above minimum retirement age (dummy) & $-4.924^{* * *}$ & -3.000 & $-5.059^{\star \star \star}$ & $-5.069^{* \star *}$ & $-4.781^{* *}$ & $-9.317^{\star \star \star}$ & $-5.245^{\star \star *}$ \\
\hline Above normal retirement age (dummy) & $-5.061^{\star \star *}$ & $-4.581^{* *}$ & $-5.005^{\star \star *}$ & $-5.399^{\star * *}$ & $-5.020^{\star \star \star}$ & -3.322 & $-5.036^{* *}$ \\
\hline Normal retirement age & & & & -0.210 & & & \\
\hline$\%$ of population group with tertiary education & $0.128^{* *}$ & $0.128^{* *}$ & $0.120^{* *}$ & $0.128^{* *}$ & 0.084 & $0.128^{\star *}$ & $0.150^{* *}$ \\
\hline Life expectancy at 65 & $2.109^{\star \star *}$ & $1.918^{* * *}$ & $2.131^{* \star *}$ & $2.142^{\star * *}$ & $1.703^{*}$ & $2.005^{\star \star *}$ & $2.134^{* * *}$ \\
\hline Age & & & & & & $-2.991^{* * *}$ & \\
\hline $\begin{array}{l}\text { Unemployment gap (\% of labour force, } 5 \text {-year moving } \\
\text { average) }\end{array}$ & $0.345^{*}$ & $0.339^{\star *}$ & & $0.331^{*}$ & $0.547^{* *}$ & $0.433^{\star *}$ & $0.358^{*}$ \\
\hline Unemployment rate (\% of labour force) & & & $-0.263^{*}$ & & & & \\
\hline Estimator & OLS & OLS & OLS & OLS & OLS & OLS & WLS \\
\hline Age fixed effects & Yes & Yes & Yes & Yes & Yes & No & Yes \\
\hline Time fixed effects & No & No & No & No & Yes & No & No \\
\hline Adjusted $\mathrm{R}^{2}$ & 0.881 & 0.881 & 0.882 & 0.881 & 0.882 & 0.866 & 0.890 \\
\hline
\end{tabular}

Note: Asterisks $(*, * *, * * *)$ indicate the statistical significance level of the coefficients $(10 \%, 5 \%, 1 \%)$. Equations are estimated with Ordinary Least Squares (OLS) or Weighted Least Squares (WLS) using heteroscedasticity-consistent standard errors clustered by country. All equations include country, sex, age and education fixed effects, as well as sex-education, sex-age and education-age interaction effects (see equation 1 above), except equation 6 which replaces the age component in fixed and interaction effects by a variable measuring age in years. Equation 5 also includes time fixed effects. All equations use an unbalanced panel of 26 countries over the 1990 -to-2017 period for a total of 30764 observations. See Annex B for a description of variables and sources.

- Participation rates drop by 4.9 percentage points at the minimum retirement age and by an additional 5.1 percentage points at the normal retirement age (blue line in Figure 9). In the specification adopted here, raising either or both retirement ages by one year affects participation rates only at those specific ages. For example, if the minimum retirement age were raised from 60 to 61 and the normal retirement age from 65 to 66, then participation rates would go up only for 61 and 65 year-olds (horizontal shift to red lines in Figure 9). The impact on the aggregate participation rate of 55-to-74 year-olds would then depend on population shares around the relevant ages, but would typically be around $1 / 4$ percentage points for both the minimum and normal pension ages. Considering that a policy reform would typically raise both pension ages at once, the total effect is around $1 / 2$ percentage point, but it is conditional on a constant level of pension wealth. In reality, raising statutory retirement ages lowers pension wealth for all 55-to-74 year-olds, imparting a positive impulse to participation (vertical shift to green line in Figure 9). In studies that do not include a measure of pension wealth, the reported effects may include the pension wealth channel implicitly. A direct comparison to previous studies thus requires using the estimated equation to simulate the impact of raising both the minimum and normal retirement ages by one year, together with the effect of these reforms on pension wealth from mandatory schemes. The resulting impacts on participation rates of 55-to-74 year-olds differ substantially across countries, reflecting differences in pension system design as well as differences in population weights around the relevant ages (Figure 10). The effect is $3 / 4$ percentage points in the median country, in line with previous studies (Table in Box 1). 
Figure 9. Illustrative age profile of conditional participation rates before and after one-year increase in statutory retirement ages

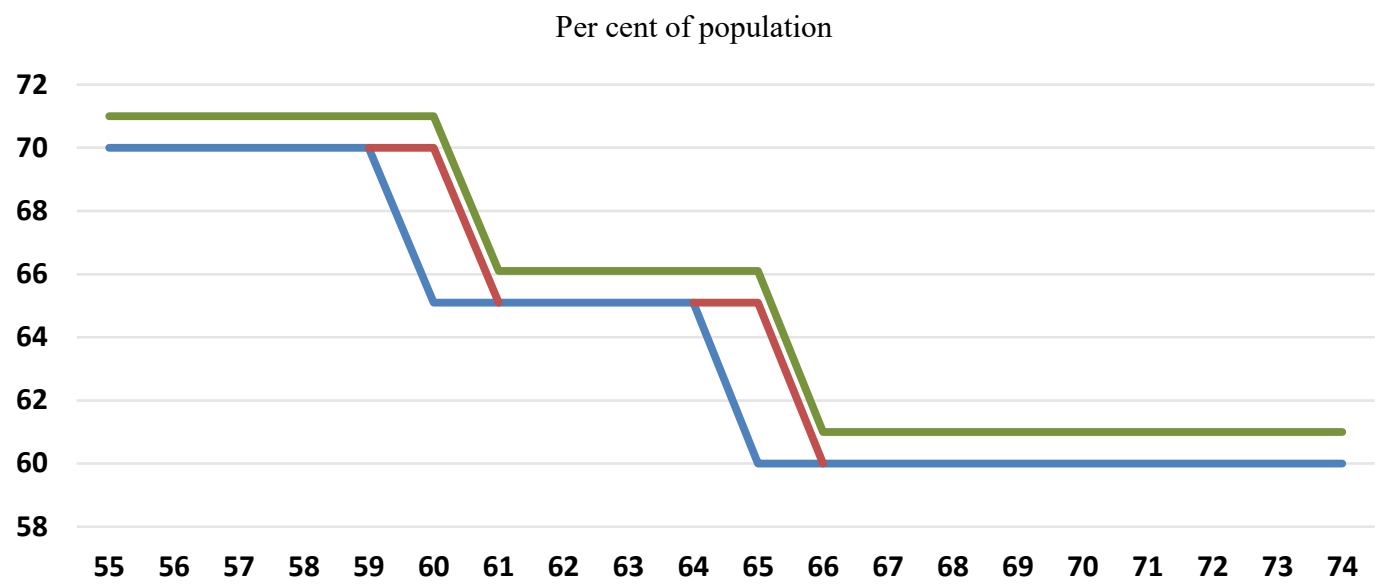

Note: The blue line shows an illustrative path for conditional age-specific participation rates given the estimated effects of statutory retirement ages, assuming that the minimum and normal retirement ages are 60 and 65 , respectively. Under the hypothesis that both statutory retirement ages are raised by one year, the red segments shows the shift in the profile coming through the estimated retirement age variables only. The green profile shows the total effect, including the resulting fall in pension wealth, which is assumed, for illustrative purposes, to raise participation rates by one percentage point at all ages.

Figure 10. Impact on participation rate of 55-to-74 year-olds of raising minimum and normal retirement ages by one year in 2017 , taking account of implied change in pension wealth

\section{Percentage points of population aged 55 to 74}

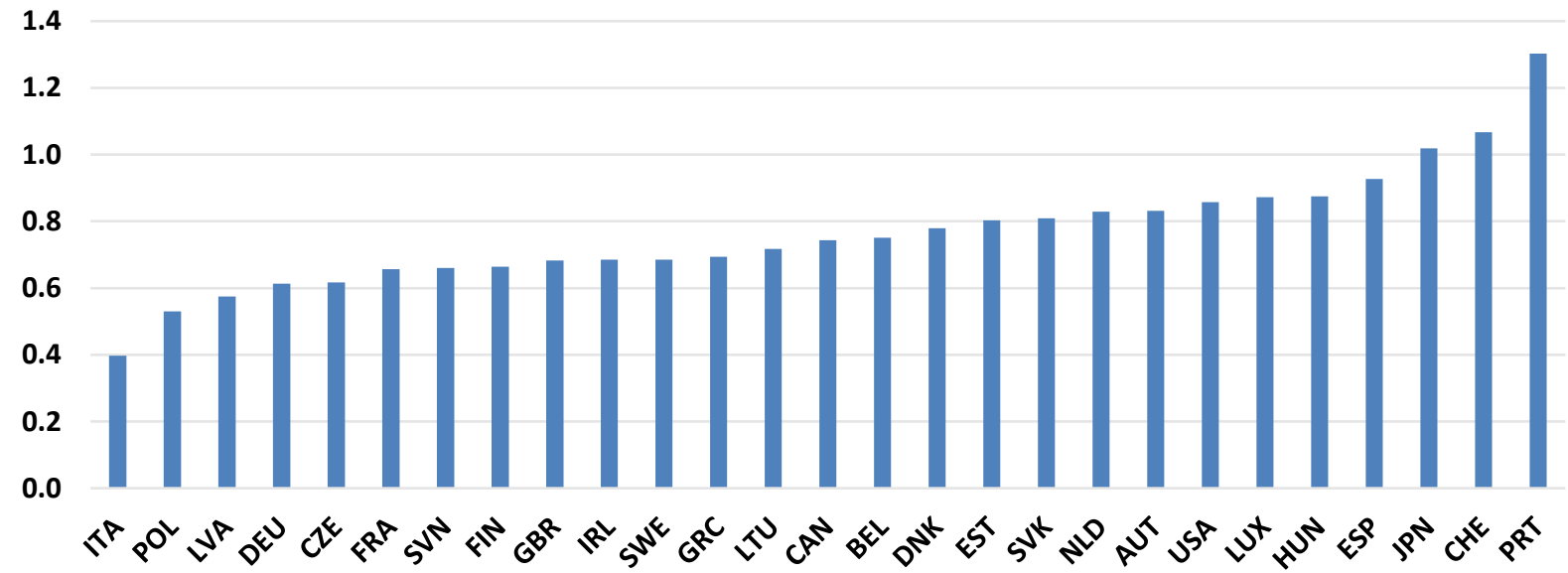

- A one-percentage point increase in the share of 55-to-74 year-olds with tertiary education raises their aggregate participation rate by about 0.2 percentage points, taking into account both the estimated coefficient on tertiary education and the education-related fixed effects, so the exact effect depends on country-specific population shares. This estimate is about half of the 0.4 found by Grigoli, Koczan and Tapalova $\left(2018_{[14]}\right)$. There are no doubt opposing forces behind this result. On the one hand, people who are more educated tend to have less physically demanding and more intellectually rewarding jobs that they might want to perform longer. On the other hand, they also tend to have higher private wealth (which is absent from the controls) and can 
therefore afford to retire earlier. The overall labour market is also different when the workforce is more highly educated.

- A one-year increase in life expectancy raises the participation rate of 55-to-74 year-olds by 2.1 percentage points. The effect has the expected sign and probably reflects more than one channel, including the capacity to work longer that comes with better health, in line with the micro-level literature (Coile, Milligan and Wise, 2016[23]), as well as movement along the labour-leisure trade-off. Using a typical exit rate profile (that of Canada), the estimated effect means that an extra year of life expectancy raises the average age of labour market exit by approximately 6 months. In other words, people choose to split an additional expected year of life roughly in half between work and retirement.

- A one-percentage point increase in the average unemployment gap over the last five years raises the participation rate of 55-to- 74 year-olds by 0.3 percentage points. The effect is not highly statistically significant, perhaps indicating that, as discussed previously, there are both pro-cyclical and counter-cyclical forces acting on participation, with pro-cyclical forces dominating on average (c.f. 3.1.8).

26. A few additional insights can be gleaned from the other specifications shown in Table 1:

- Column 2 replaces the pension wealth indicator by the pension replacement rate. Its effect appears large; however, the minimum retirement age dummy variable is no longer statistically significant. The two effects should be understood together: because the replacement rate is by definition zero before the minimum retirement age, the replacement rate indicator captures the effect of being above the minimum retirement age as well as the level of the replacement rate itself.

- Column 3 replaces the unemployment gap variable with the unemployment rate to compare with the result of Blöndal and Scarpetta $\left(1999_{[5]}\right)$, who found that a one-percentage point increase in the unemployment rate over the 1971-to-1995 period was associated with a 0.6 to 0.9 percentage point fall in the participation rate of 55-to-64 year-old males $(p<0.01)$. This and other of their findings (see Box 1$)$ are suggestive of a proclivity for using the unemployment system as a route toward early retirement over this period. The sample period used here begins toward the end-point of Blöndal and Scarpetta's and the estimated coefficient on the unemployment rate is less than half of theirs and much less statistically significant $(p<0.10)$, suggesting that the role of the unemployment system as an early retirement pathway has diminished.

- One possible issue with the retirement age dummies is the implicit assumption that raising them would not affect labour supply below these ages. So column 4 includes the dummies and the normal retirement age together to capture simultaneously the discontinuities in age-specific participation rates at the statutory ages as well as the signalling effect on younger people. The new coefficient is not statistically significant, suggesting that statutory retirement ages have little impact on participation below those specific ages (conditional on constant pension wealth). The minimum retirement age was also tried, as well as lags of both minimum and normal retirement ages - to account for the possibility of a delayed reaction to reforms. None were statistically significant.

- Column 5 includes time fixed effects, which take away some of the explanatory power of life expectancy and education, as could be expected given that these indicators share a positive time trend across countries. The effect of tertiary education must include not 
only the variable reported in Table 1, but also composition effects through the estimated education-related fixed effects, which remain statistically significant. This calculation reveals that raising the tertiary education share by one percentage point would raise the participation rate of 55-to- 74 year-olds by almost 0.2 percentage points, about the same as in the baseline specification. Moreover, only one of the 26 estimated time fixed effects is statistically significant (1991, probably due to the recession at the time) so time fixed effects are left out of the baseline specification.

- The age fixed effects included in the baseline specification may absorb some of the impact of mandatory pension systems, particularly in the 60-to-65 age range where these systems affect incentives most strongly. To examine this possibility, column 6 replaces indicator variables for age by a variable measuring age in both fixed and interaction effects, thus imposing a linearity constraint to the age component of conditional participation rates. The estimated coefficient on pension wealth and the estimated drop in participation at the minimum retirement age both increase relative to the baseline specification, but the estimated coefficient on the normal retirement age declines and is no longer statistically significant. Together, changes in magnitudes for the three coefficients suggest that age fixed effects may indeed absorb some of the incentive effects of mandatory pension systems. At the same time, the age fixed effects are important to absorb the influence of occupational pension plans and other non-mandatory pension schemes, which also affect the retirement decision primarily in the 60-to-65 age range and which are missing specific controls in the regression setup. There is no a priori reason to expect these other effects to be linear in the age dimension, so the linearity constraint is not retained in the baseline specification.

- Column 7 is the same as column 1 but based on the weighted least squares (WLS) estimator instead of ordinary least squares (OLS) to account for the variation in population sizes behind each observation, which could affect coefficient estimates in case of heterogeneous effects across sex, age and education groups, in particular for the pension wealth variable. ${ }^{7}$ The similarity between both sets of results suggests that heterogeneity does not affect average effects in the current application.

\subsection{Estimated fixed effects from the baseline specification}

27. The country fixed effects (not reported in Table 1) capture time-invariant, country-specific factors. Ideally, such fixed effects would not be necessary and systematic country differences in participation (shown in Figure 2) would be 'explained' by explicit factors, such as the flexibility of labour markets. In practice, however, although many labour market policy and other indicators were tried (as $X_{j}$ ), they were not found to be statistically significant and/or robust. ${ }^{8}$ Moreover, because they are only available after a substantial time lag, their inclusion cuts the sample period short by several years. Finally, even if a few of these variables could be included, there would always remain some

\footnotetext{
${ }^{7}$ This is because the pension wealth indicator varies not only in the country and year dimensions, but also in the age, sex and education dimensions.

${ }^{8}$ The following variables were tested as explanatory variables but were not found to be statistically significant or robust: union density, tax wedges, openness to trade, public spending on active labour market policies, share of service-sector employment; urbanisation rate; restrictiveness of employment protection legislation; excess coverage of collective labour agreements, wage setting coordination and public spending on early retirement benefits.
} 
unaccounted for country specificities. Country fixed effects are thus important to prevent a potentially important source of omitted variable bias.

28. As hinted above, the absence of year fixed effects, or country-specific time trends, in the baseline specification creates a risk of spuriously assigning to life expectancy and educational attainment positive effects on participation due to shared positive time trends. This is an important caveat to the estimation strategy adopted here. Even though there are solid theoretical reasons to expect a positive relationship between both factors and labour supply, the association measured here could well be overestimated. The typical alternative in such cases, first-differencing both the dependent and explanatory variables, was not retained because the dataset already suffers from a number of missing values which are not uniformly distributed across countries and first-differencing would have resulted in a much larger number of missing observations. The results are also easier to compare to Gal and Theising $\left(2015_{[21]}\right)$ and Grigoli, Koczan and Tapalova $\left(2018_{[14]}\right)$, who likewise rely on level specifications.

29. The sex, age, education fixed effects and their interactions (not reported in Table 1) capture differences in the lifecycle profiles of participation rates for different demographic groups. They are almost all statistically significant and have the expected patterns. Participation rates for women tend to be lower than men's ( 23 percentage points lower on average), but also tend to decline less sharply with age, ostensibly because they start from a lower level (Figure 11). Education correlates positively with participation rates for both sexes, with a gain of approximately 10 percentage points when going up one level of educational attainment (Figure 12). Age profiles of participation rates for different sex-education combinations also show subtle differences but, although statistically significant, these are second-order in magnitude.

Figure 11. Estimated differences in participation rates relative to 55 year-old men According to estimated fixed effects from baseline specification (Table 1, column 1)

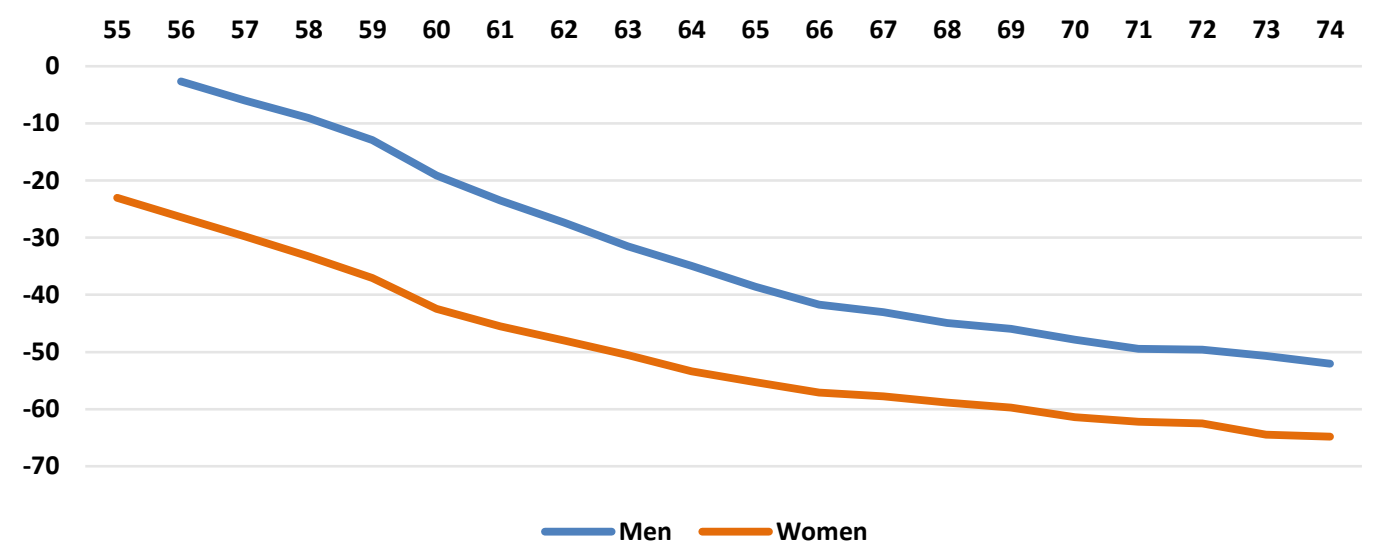

Note: As they come from an estimated equation including other controls, these differences should be interpreted as conditional on the other indicators (such as pension wealth, statutory retirement ages, etc.). 
Figure 12. Estimated differences in participation rates relative to men with low education

According to estimated fixed effects from baseline specification (Table 1, column 1)

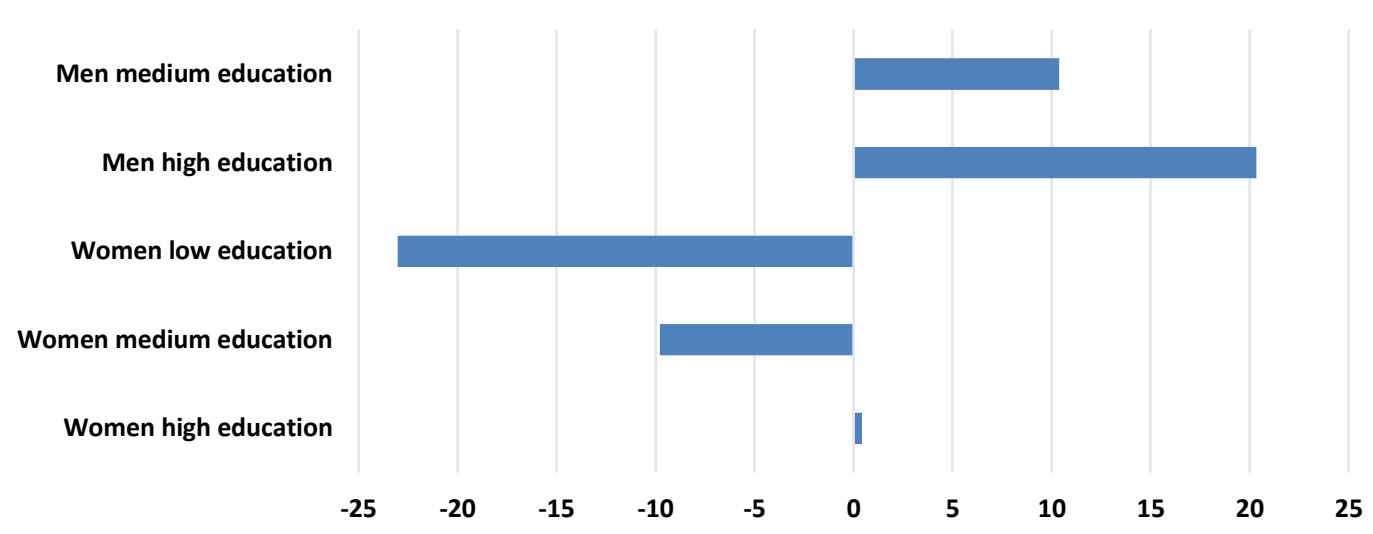

Note: As they come from an estimated equation including other controls, these differences should be interpreted as conditional on the other indicators (such as pension wealth, statutory retirement ages, etc.).

\subsection{Cross-country heterogeneity in policy effects}

30. Statutory retirement ages and pension wealth have heterogeneous impacts across countries. A specification allowing for country-specific coefficients on minimum retirement age, normal retirement age and pension wealth reveals that the normal age tends to have a smaller impact on participation when the minimum age has a larger one, and vice-versa (Figure 13). This is not true everywhere, however, likely reflecting heterogeneity in the design of social security systems with their various features, their interactions and interactions with the private pension system as well. Importantly, these effects are also averages over a fairly long estimation period, during which many countries reformed their pension systems. For instance, Sweden reformed its pension system at the end of the 1990s, moving gradually from a defined-benefit to a notional defined-contribution system. The large negative effect estimated for its normal retirement age likely reflects the pre-reform pension system with a normal retirement age of 65 and an important spike in exit rates at this specific age. In the new system, the normal pension age would be better described as a flexible 'age band' for retirement. There may still be a tendency for people to retire at 65 , but driven more by habit than by the system itself, except for low-earners, who cannot receive a guaranteed pension before that age. To a certain extent, then, the estimated coefficients reflect past features of the pension system and their persistent impacts on behaviour. 
Figure 13. Cross-country heterogeneity in the impact of statutory retirement ages

Impact of being older than the minimum (green) or normal (blue) retirement age on labour market participation, percentage points of population

15

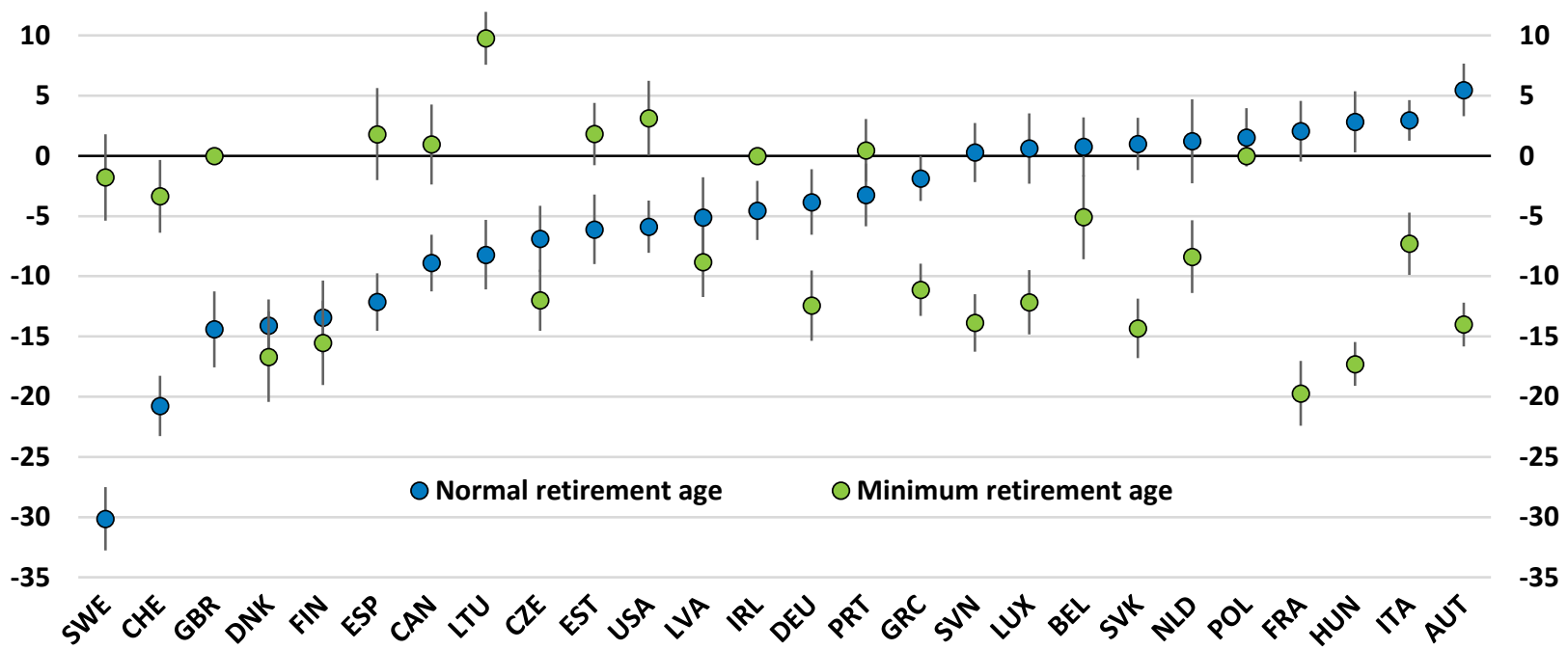

Note: The chart reports estimated coefficients for interaction effects between country indicator variables and the statutory retirement age dummies in a regression model allowing country-specific coefficients on retirement ages and pension wealth, but otherwise identical to the baseline specification (Table 1, column 1). The dots show the point estimates and the vertical lines the $95 \%$ confidence intervals. When the coefficient is zero with no confidence interval, it is because the variable was dropped from the regression due to collinearity.

31. The impact of pension wealth on participation also shows a lot of cross-country heterogeneity in the alternative specification. The estimated coefficients are negative and statistically significant, as expected, for only 11 of the 26 countries (Figure 14). The reasons behind this heterogeneity are not clear, but one factor could be generosity of the social security system. In countries where systems are less generous, for instance in Anglo-Saxon countries where non-mandatory occupational pension plans play a greater role, pension wealth from mandatory pension schemes may be too low to have an important influence on labour supply behaviour.

32. When using these country-specific coefficients on retirement ages and pension wealth to simulate a one-year increase in both the minimum and normal retirement ages, taking into account implied changes in pension wealth, the total effects on the participation rate of 55-to-74 year-olds vary even more across countries than suggested by the baseline specification (effects shown in Figure 10). They go as high as 1.5-1.7 in a few countries, more than twice the median effect from the baseline equation. 
Figure 14. Cross-country heterogeneity in the impact of pension wealth

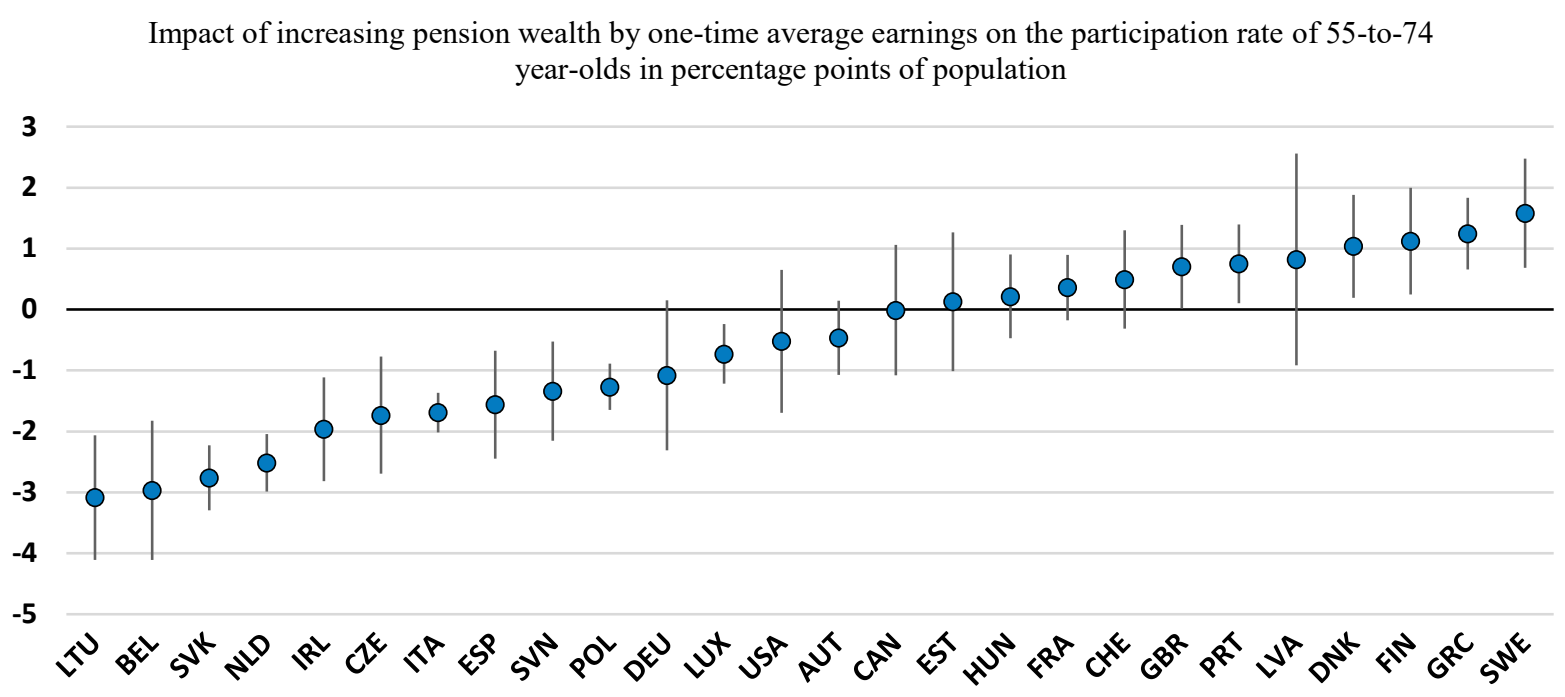

Note: The chart reports estimated coefficients for interaction effects between country indicator variables and the pension wealth variable in a regression model allowing country-specific coefficients on retirement ages and pension wealth, but otherwise identical to the baseline specification (Table 1, column 1). The dots show the point estimates and the vertical lines the $95 \%$ confidence intervals.

\section{Historical decomposition and projection of participation rates for 55-to-74 year- olds using the baseline specification}

\subsection{Evolution of participation rates between 2002 and 2017}

33. Among the 27 countries considered here, changes in the participation rates of 55 to-74 year-olds between 2002 and 2017 range from 11/4 percentage points (Portugal) to 211/2 percentage points (Germany), the median increase being 10.9 percentage points (Slovenia). Decomposing the change using the baseline specification from the previous section yields the following (Figure 15)

- Rising life expectancy accounts for between 31/4 (Greece) and 6 (Estonia) percentage points of increases in participation rates. It accounts for $4 \frac{1}{2}$ percentage points of the increase in the median country, more than a third of the total.

- Rising educational attainment accounts for between 23/4 (United States) and 101/2 (Finland) percentage points of increases in participation rates, or $4 \frac{1}{4}$ in the median country, also more than a third of the total. ${ }^{10}$

9 The contribution of each factor is obtained by letting the relevant factor(s) evolve over the 2002-to-2017 period while holding other factors constant at their 2002 values and computing the predicted change in the participation rate of 55-to-74 year-olds using the estimated equation. Factors include population shares in different age/sex/education groups, which affect the aggregate participation rate of 55-to-74 year-olds through composition effects given the estimated fixed and interaction effects.

10 The contributions of 'education' is obtained by letting population shares of different education groups vary over the period, as well as the share of 55-to-74 year-olds with tertiary education entering as a right-hand side variable. All of the resulting predicted change in participation is 
- Increases in both minimum and normal retirement ages account for between zero (Sweden, Japan, Luxembourg and Canada) and 21/2 percentage points (Hungary) of changes to participation rates, or 1 percentage point in the median country. These contributions are conditional on constant pension wealth, so they can be interpreted as 'signalling effects' of policy changes, without the associated financial effects.

- Pension wealth declined in most countries, contributing about $1 / 4$ percentage point to the increase in the participation rate in the median country, and as much as $1 \frac{3 / 4}{4}$ in Estonia and the United Kingdom. In some countries, however, rising pension wealth pushed the participation rate down, by as much as $2^{1 / 4}$ percentage points in Lithuania. These contributions capture 'pure policy change' effects. Often, changes in pension wealth are due to changes in statutory retirement ages. When this is the case, the contributions here reflect the reforms' impacts on financial incentives, with 'signalling effects' captured by the 'statutory retirement ages' component, as mentioned previously.

- Changes to the age structure of the population aged 55 to 74 contributed 0.6 percentage points to the increase in participation rate in the median country, but with important cross-country differences. ${ }^{11}$ It pushed down the participation rate for this age group in about half of the countries and by as much as 5 percentage points in Japan and Sweden. These are countries where the share of 55-64 declined relative to the share of 65-74. In the other half of countries, the opposite occurred and the 55-to-74 year-olds became, on average, younger over the period considered. This pushed up the participation rate by as much as $2 \frac{1}{4}$ percentage points in Estonia.

- Other factors - changes in the unemployment gap, changes in the sex ratio and interaction effects not attributable to a specific factor - explain little of the change in participation rates in most countries.

- Because of the model's imperfect fit as well as differences between the top-down (actual) and bottom-up (model) aggregation of participation rates, there is an unexplained component to the rise of participation rates in most countries. In the median country this component is zero, but it is substantial in some cases. The model over predicts the increase in participation rates in about half of the countries, by as much as 9 percentage points in Portugal, and under predicts the increase in participation rates in the other half of countries, by as much as 12 percentage points in Germany.

assigned to the 'education' factor, even though some of it comes from differences in pension wealth between education groups.

11 The contributions of 'age composition' is obtained by letting population shares in different age groups vary over the period. All of the resulting predicted change in participation is assigned to the 'age composition' factor, even though some of it comes from differences in pension wealth between age groups. 
Figure 15. Decomposition of change in participation rate of 55-to-74 year-olds

Change 2002 to 2017 , percentage points of the population aged 55 to 74

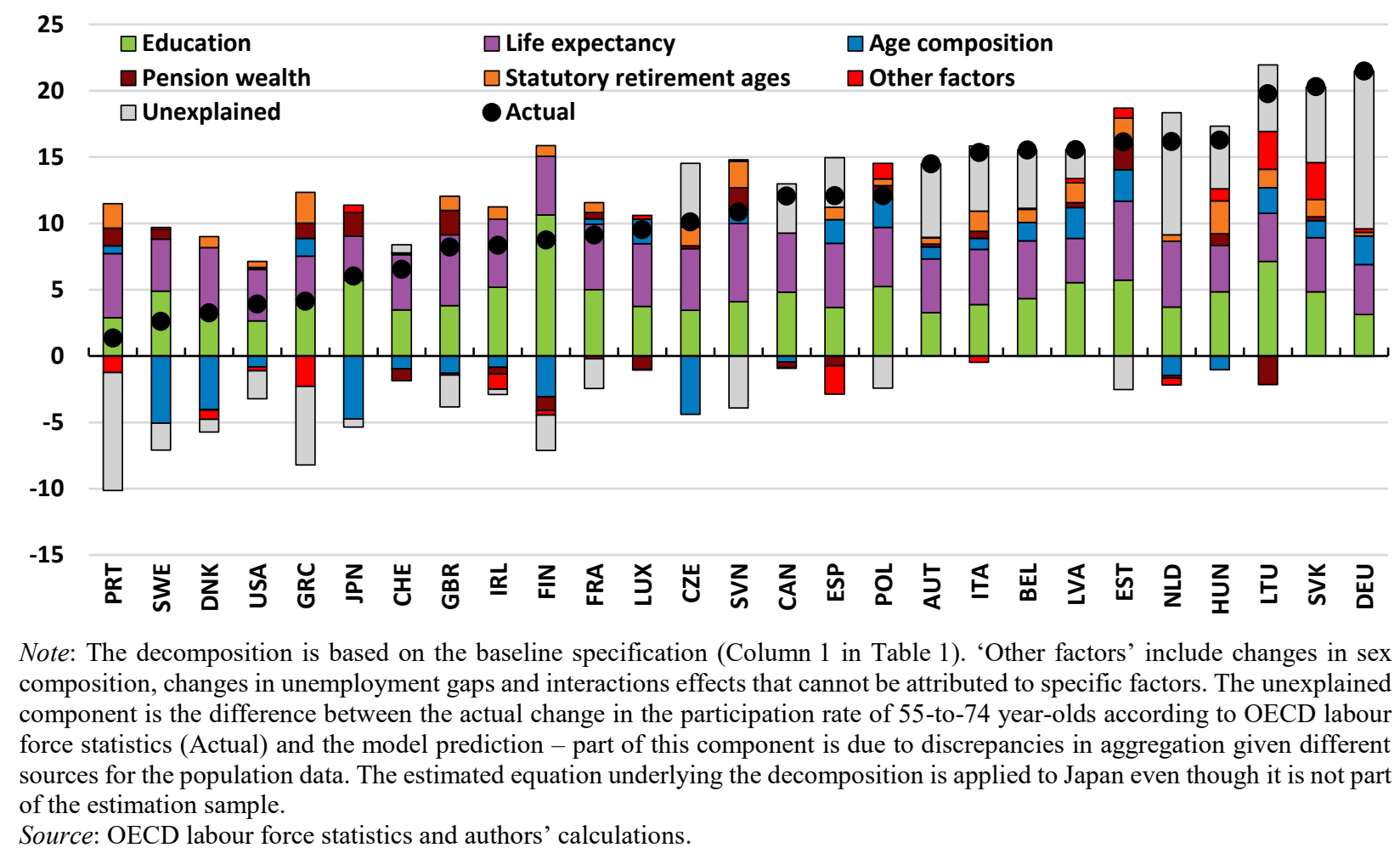

34. The decomposition presented here suggests that policy reforms have played only a small role in the rise of participation rates for older people since 2002. However, it must be emphasised that only a subset of retirement incentives embedded in social security systems are taken into account. Notably, changing financial incentives associated with the gradual elimination of early retirement pathways from the mid-1990s onwards could not be included in the empirical framework. Therefore, the results are not necessarily inconsistent with the findings from earlier studies, discussed previously, of a large role for financial retirement incentives in explaining labour supply decisions of older people. In addition, it is, in principle, possible for persistent level differences in participation rates across countries to be largely due to differences in social security systems; and for their evolution since 2002 to have been mainly driven by other factors.

35. The findings that rising educational attainment and life expectancy account for a large part of the increase in labour market participation of older people since 2002 point to a major role for policy reforms in these areas going back several decades, given the long lagged involved. But they also present a puzzle: why did these trends not push up participation in the 1980s and 1990s, when it fell instead? The answer is that they may well have, but with governments pushing hard enough the other way to overcome the secular trends, notably by encouraging use of early retirement pathways. With these pathways largely closed by the early 2000 s, policy attention has turned to raising statutory retirement ages. Reforms on this score have been mild, however, especially in relation to increases in life expectancy. So secular influences might have reasserted themselves and driven most of the increase in participation since the early 2000s. 


\subsection{Projecting the future evolution of participation rates to 2030}

36. The omission of early retirement pathways in unemployment and disability insurance schemes from the policy indicators is less of a concern when looking forward and projecting the future evolution of participation, because these pathways cannot be closed again. Future policy reforms to influence old-age participation will likely come mainly through changes in statutory retirement ages and pension wealth. Using the estimated equation to project the evolution of participation rates requires projections of the explanatory variables and a number of assumptions:

- The age/sex structure of the 55-to-74 year-old population follows projections by the United Nations Population Division and the evolution of educational attainment follows projections by the Wittgenstein Centre for Demography and Global Human Capital.

- Life expectancy follows projections made by the United Nations Population Division. The median increase between 2017 and 2030 is 1.8 years for men and 1.4 for women.

- Pension wealth follows projections made for this paper by the Directorate for Employment, Labour and Social Affairs of the OECD based on current legislation.

- Minimum and normal pension ages evolve according to current legislation.

- The unemployment gap estimated for 2017 is assumed to close over the next few years and remain zero thereafter.

37. On the basis of these projections and assumptions, the estimated model sees participation rates for 55-to-74 year-olds rising through 2030, by 3.4 percentage points for the median country but ranging from $-2 \frac{1}{4}$ percentage points (Germany) to $11 \frac{1}{2}$ percentage points (Japan) (Figure 16). Other takeaways from the projections include:

- Gains in life expectancy make the largest contribution to rising participation, with a median contribution of 3.4 percentage points. Using the rule-of-thumb calculated previously, this translates into a $91 / 2$-month increase in the average age of labour market exit between 2017 and 2030 .

- Rising educational attainment makes the second-largest contribution with a median of 2.4 percentage points, coming both from a population composition effect (more educated people have higher participation rates) and a labour market effect (a more educated populace tends to raise participation rates for everyone). The contribution is positive in all countries, except the United States, where it is flat, and Germany, where the share of 55-to-74 year-olds with tertiary education is projected to fall by 2030 .

- Changes in the age distribution within the 55-to-74 age group push down the participation rate by 2 percentage points in the median country, but as much as 5.4 percentage points in Germany. Particular age dynamics within this age group contribute positively to participation in a few countries, and substantially so in the Czech Republic and Japan.

- Already-legislated changes to statutory retirement ages push up the participation rate of 55-to-74 year-olds by $1 / 2$ percentage point in the median country. This component is zero in countries where legal retirement ages are not expected to change, and as much as 1.2 percentage points in countries where they are set to keep rising along with life expectancy (e.g. Denmark and the United Kingdom). 
- Pension wealth stays mostly constant in the projections despite legislated increases in statutory retirement ages in many countries because life expectancy rises as well.

- The closing of still-high unemployment gaps push up participation rates in Spain and Greece (this effect is subsumed in the 'other factors' component).

Figure 16. Projected change in participation rates of 55-to-74 year-olds between 2017 and 2030 according to estimated model

Percentage points of the population aged 55 to 74

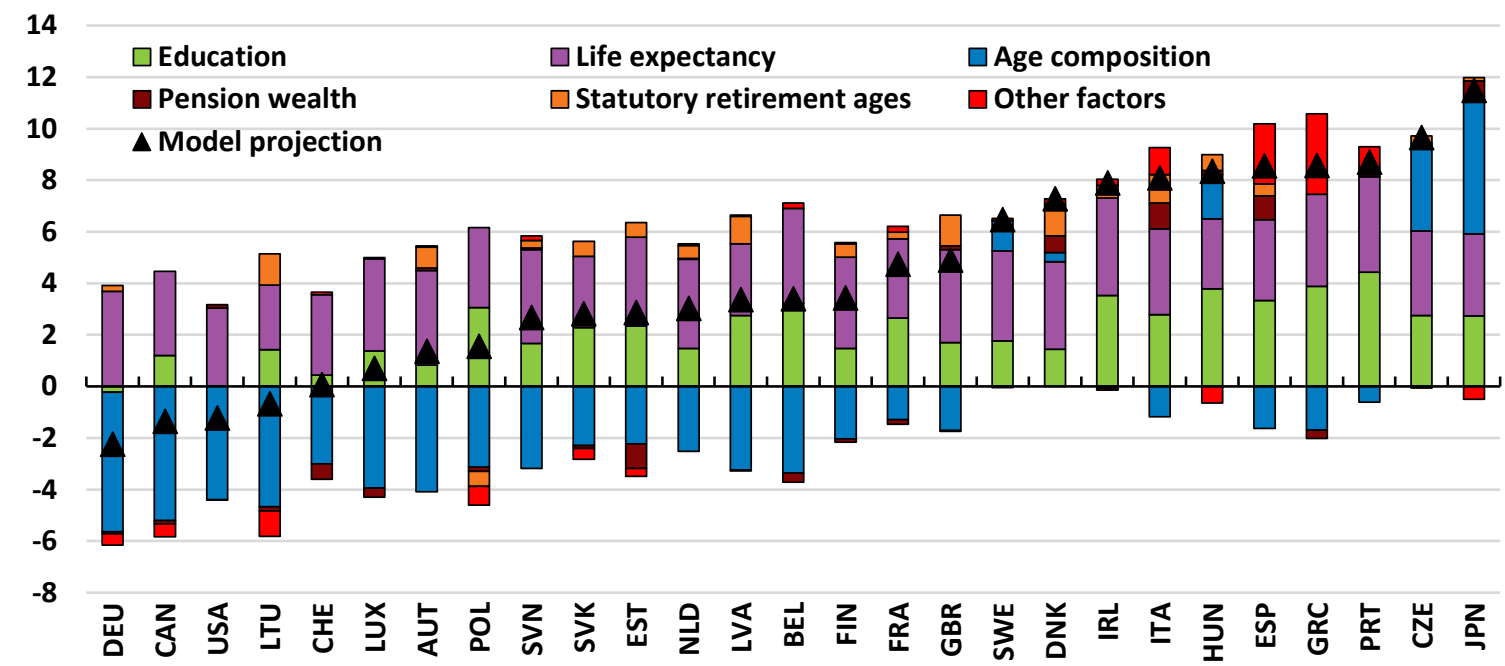

Note: The decomposition is based on the baseline specification (Column 1 in Table 1). 'Other factors' include the change in the sex composition, the change in the unemployment gap and interactions effects that cannot be attributed to specific factors. The estimated equation underlying the projection is applied to Japan even though Japan is not part of the estimation sample.

38. In a hypothetical scenario in which age-specific participation rates remain constant at 2017 levels across the full 15-to-74 age range, population ageing depresses real GDP per capita by $5 \frac{1}{2}$ per cent in the median country by 2030, relative to 2017 (Figure 17). ${ }^{12}$ This is a pure demographic effect occurring because of the declining profile of age-specific participation rates. The effect is strongest, up to $8-9 \%$, where ageing is sharpest and the downward slope of the age profile steepest, notably in Japan, Spain, Latvia, Lithuania, the Czech Republic and Slovenia. Projected changes in participation rates of 55-to-74 year-olds due to components other than age composition offset some, but not all, of these losses, 3 percentage points in the median country (United Kingdom), but as much as 5-6 percentage points in Spain, Greece and Italy if current unemployment gaps close as assumed (Figure 17). In most countries, only a small part of these gains are driven by planned pension system reforms, but as much as $1 / 2$ percentage point in Denmark and the United Kingdom, and $3 / 4$ percentage point in Italy, given legislation in these countries tying the evolution of retirement ages to life expectancy.

\footnotetext{
${ }^{12}$ The simulation takes into account the impact of the projected rise in participation on employmentto-population ratios given specific countries' demographics, but it assumes no change to labour productivity.
} 
Figure 17. Impact of change in old-age participation on real GDP per capita by 2030

Per cent difference from 2017

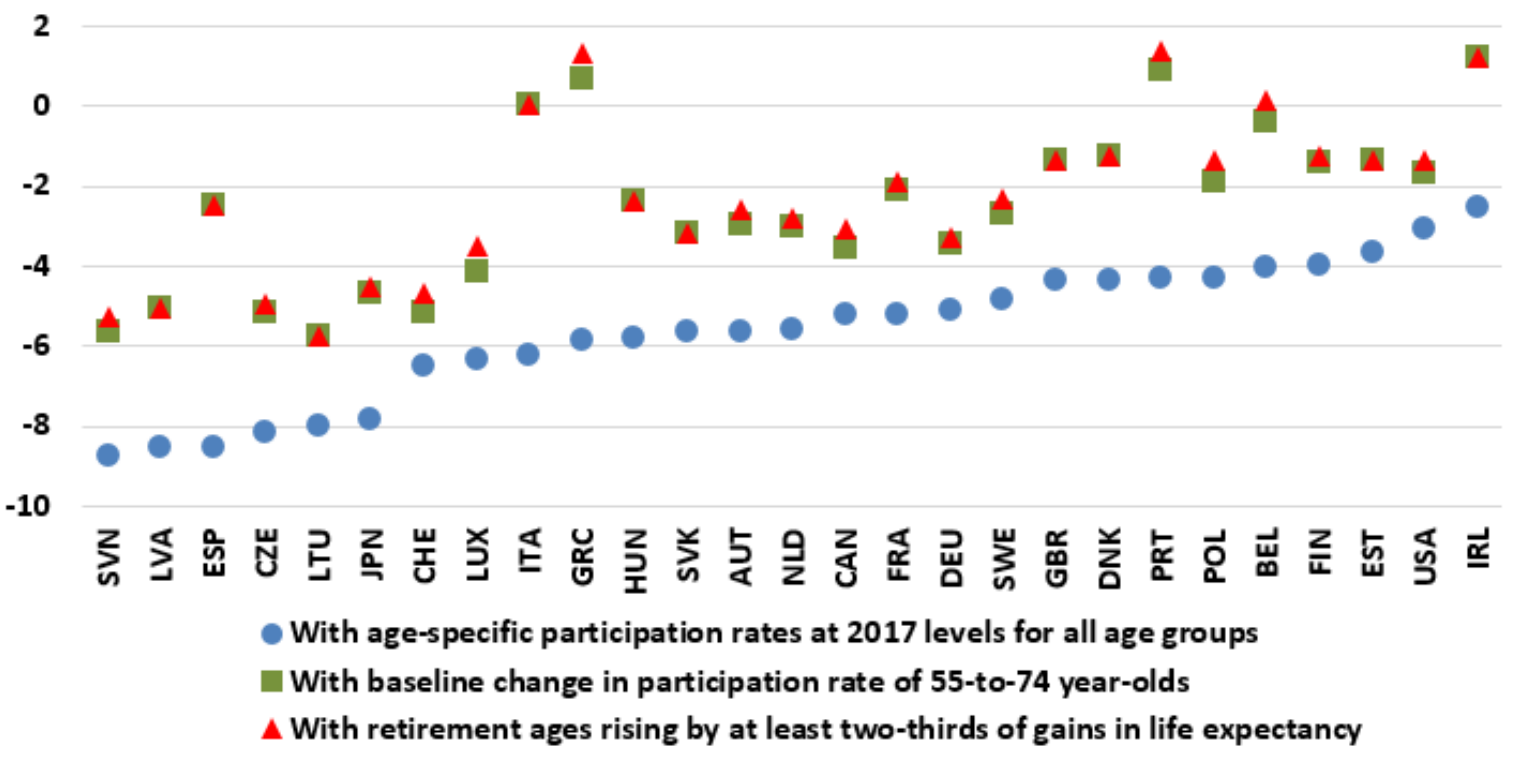

39. Rising old-age participation would help alleviate the pressures of ageing on public finances, through a wider base for taxes and social security contributions and lower transfers. In a financially balanced pay-as-you-go pension system, a $1 \%$ fall in the effective old-age support ratio (number of employees relative to the number of retirees) necessitates either a $1 \%$ fall in the average pension relative to the average wage, or a $1 \%$ increase in the contribution rate (Boulhol and Geppert, 2018[24] ). In the hypothetical scenario mentioned above in which age-specific participation rates remain constant at 2017 levels, the effective old-age support ratio falls by $21 \%$ in the median country by 2030 , and as much as $30 \%$ in Spain. Projected changes in participation rates of 55-to-74 year-olds due to components other than age composition help offset some of the decline in support ratios, by about 7 percentage points in the median country, but 9-10 percentage points in Belgium, Ireland and Latvia and 12-13 percentage points in Spain, Italy, Portugal and Greece. Policies to support old-age employment would therefore help alleviate any cuts to benefits or increases in contribution rates in pay-as-you-go pension systems.

40. To consider the potential for reforms to raise participation in all countries given current legislation, an alternative scenario assumes that both minimum and normal retirement ages rise by two thirds of the projected increase in sex-specific life expectancy at 65 , unless current legislation implies a faster increase, in which case the legislated increases are applied. The simulation draws attention to countries that have not legislated any change to minimum or normal retirement ages for the coming decade, and could in this sense be considered to have more 'room for reform'. The gains in terms of participation rates of 55-to-74 year-olds could reach 1-1.4 percentage points for the most affected countries (Figure 18). These translate into GDP per capita gains between $1 / 2$ and $2 / 3$ per cent by 2030 and increases in support ratios of $1 \frac{1}{4-1}-1 / 2$ percentage points, with corresponding declines in fiscal pressure on pay-as-you-go pension systems (Figure 17). To emphasise a point made previously, the projections in this section being based on estimated average effects; some countries may in reality be able to benefit from larger impacts (c.f. section 4.3). 
Figure 18. Additional increase in participation rate of 55-to-74 year-olds if minimum and normal retirement ages rise by at least two-thirds of gains in life expectancy at 65

Change 2017 to 2030 , percentage points of the population aged 55 to 74

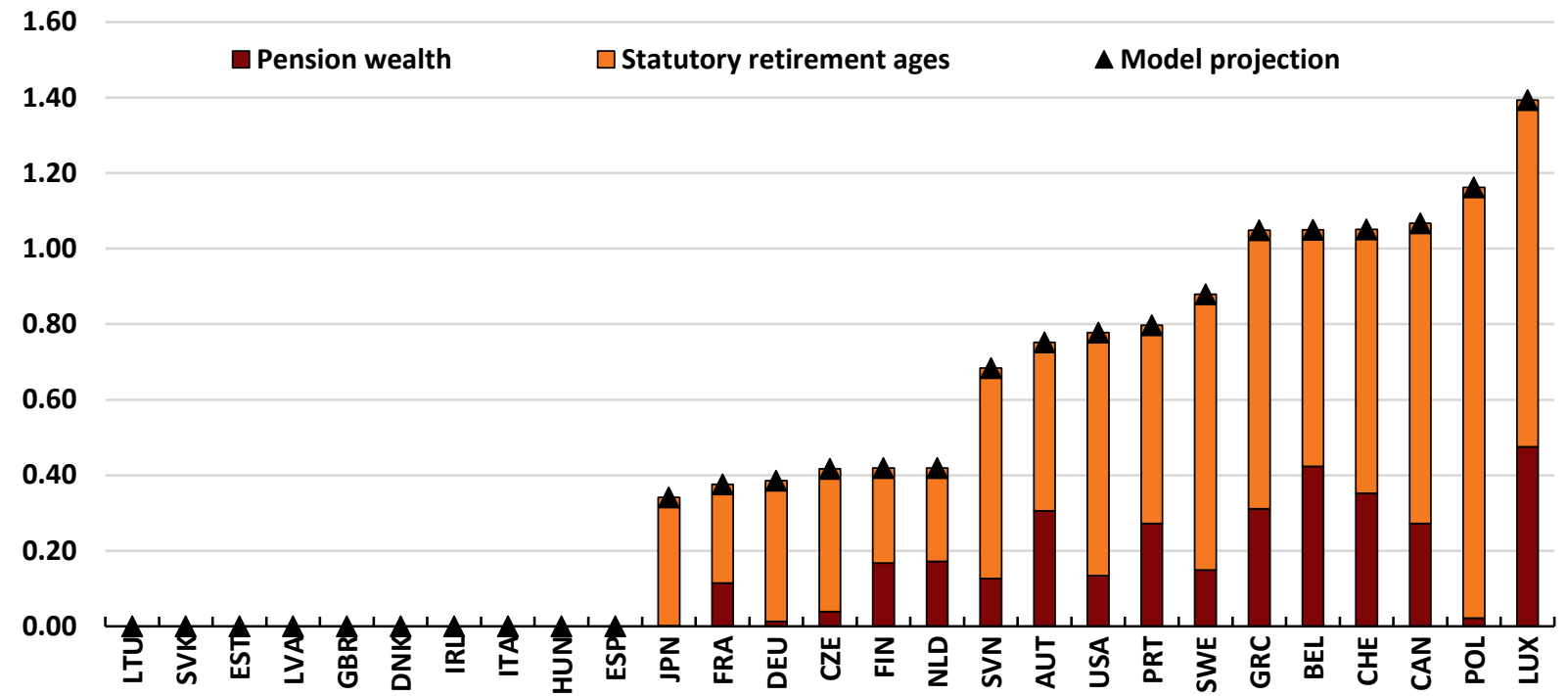

Note: The simulation assumes minimum and normal retirement ages rise by two-thirds of the projected increase in life expectancy at 65 , unless they are already planned to rise as fast or faster than this, in which case the planned increases are kept and the chart shows a zero effect. In the Czech Republic, France, Germany, Japan and Portugal, only the minimum retirement age increases in this scenario. Pension wealth is less sensitive to a change in the minimum than to the normal retirement age, which explains why the pension wealth component is relatively small. 


\section{References}

Balleer, A., R. Gómez-Salvador and J. Turunen (2009), "Labour Force Participation in the Euro Area: A Cohort Based Analysis", Working Paper Series, No. 1049, European Central Bank.

Blöndal, S. and S. Scarpetta (1999), "The Retirement Decision in OECD Countries", OECD Economics Department Working Papers, No. 202, OECD, Paris, https://doi.org/10.1787/565174210530.

Börsch-Supan, A. and C. Coile (2018), "Social Security Programs and Retirement Around the World: Reforms and Retirement Incentives - Introduction and Summary", NBER Working Papers, No. 25280, National Bureau of Economic Research, Cambridge, MA, https://www.nber.org/papers/w25280.pdf.

Boulhol, H. and C. Geppert (2018), "Population ageing: Pension policies alone will not prevent the decline in the relative size of the labour force", $V O X, \mathrm{CEPR}$, https://voxeu.org/article/effect-population-ageing-pensions.

Chang, Y. and S. Kim (2007), "Heterogeneity and Aggregation: Implications for Labor-Market Fluctuations", American Economic Review, Vol. 97/5, pp. 1939-1956.

Coile, C., K. Milligan and D. Wise (2018), "Social Security Programs and Retirement Around the World: Working Longer - Introduction and Summary", NBER Working Papers, No. 24584, National Bureau of Economic Research, Cambridge, MA, https://www.nber.org/papers/w24584.pdf.

Coile, C., K. Milligan and D. Wise (2016), "Social Security and Retirement Programs Around the World: The Capacity to Work at Older Ages - Introduction and Summary", NBER Working Papers, No. 21939, National Bureau of Economic Research, Cambridge, MA.

Currie, J. and B. Madrian (1999), "Health, Health Insurance and the Labor Market", in Ashenfelter, O. and D. Card (eds.), Handbook of Labor Economics Vol. 3, Elsevier Science B.V., Amsterdam.

Darby, J., R. Hart and M. Vecchi (2001), "Labour Force Participation and the Business Cycle: A Comparative Analysis of France, Japan, Sweden and the United States", Japan and the World Economy, Vol. 13/2, pp. 113-133.

Duval, R. (2004), "Retirement Behaviour in OECD Countries: Impact of Old-Age Pension Schemes and Other Social Transfer Programmes”, OECD Economic Studies, Vol. 2003/2, pp. 7-50.

Fallick, B. and J. Pingle (2007), “A Cohort-Based Model of Labor Force Participation”, Finance and Economics Discussion Series, No. 2007-09, Federal Reserve Board, Washington, DC. 
Gal, P. and A. Theising (2015), "The macroeconomic impact of structural policies on labour market outcomes in OECD countries: A reassessment", OECD Economics Department Working Papers, No. 1271, OECD Publishing, Paris, https://dx.doi.org/10.1787/5jrqc6t8ktjfen.

Grigoli, F., Z. Koczan and P. Tapalova (2018), “A Cohort-Based Analysis of Labour Force Participation for Advanced Economies", IMF Working Papers, No. 18/120, International Monetary Fund, Washington, DC.

Grigoli, F., Z. Koczan and P. Tapalova (2018), "Drivers of Labor Force Participation in Advanced Economies: Macro and Micro Evidence", IMF Working Papers, No. 18/150, International Monetary Fund, Washington, DC.

Gruber, J. and D. Wise (1999), Social Security and Retirement Around the World, University of Chicago Press, Chicago.

Guillemette, Y. and D. Turner (2018), "The Long View: Scenarios for the World Economy to 2060”, OECD Economic Policy Papers, No. 22, OECD, Paris, https://doi.org/10.1787/b4f4e03e-en.

Kalwij, A. and F. Vermeulen (2008), "Health and Labour Force Participation of Older People in Europe: What Do Objective Health Indicators Add to the Analysis?", Health Economics, Vol. 17.

Lutz, W., W. Butz and S. KC (2014), World Population and Human Capital in the Twenty-First Century, Oxford University Press, London.

OECD (2018), Pension Outlook 2018, OECD Publishing, Paris, https://doi.org/10.1787/pens_outlook-2018-en.

OECD (2018), Putting Faces to the Jobs At Risk of Automation, OECD, Paris, http://www.oecd.org/els/emp/future-of-work/Automation-policy-brief-2018.pdf.

OECD (2014), OECD Employment Outlook, OECD Publishing, Paris.

OECD (2010), Sickness, Disability and Work: Breaking the Barriers: A Synthesis of Findings across OECD Countries, OECD Publishing, Paris, https://doi.org/10.1787/9789264088856en.

Piketty, T. (2014), Capital in the 21st Century, Harvard University Press, Cambridge, MA.

Thévenon, O. (2013), "Drivers of Female Labour Force Participation in the OECD", OECD Social, Employment and Migration Working Papers, No. 145, OECD Publishing, Paris, http://dx.doi.org/10.1787/5k46cvrgnms6-en.

Yum, M. (2018), "On the distribution of wealth and employment", Review of Economic Dynamics, Vol. 30, pp. 86-105. 


\section{Annex A. Individual country charts for participation rates}

Figure A.1. Aggregate participation rates for 55-to-74 year-olds

Per cent of population aged 55 to 74

AUS
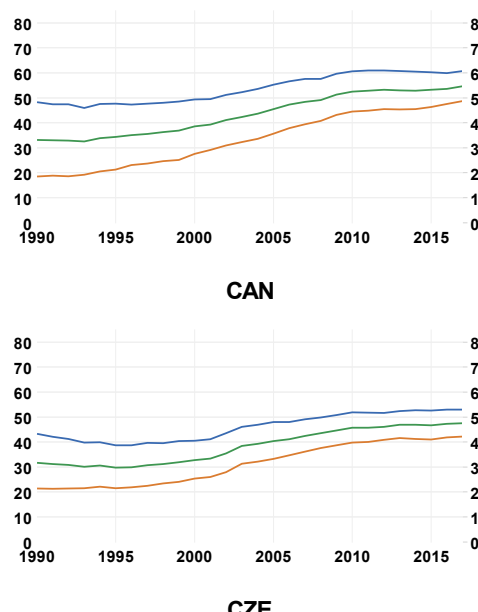

CZE

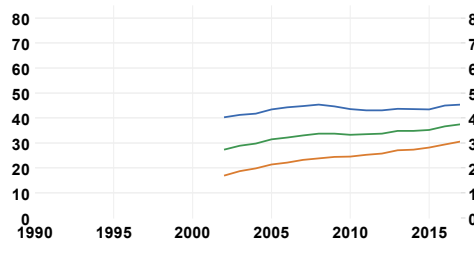

ESP

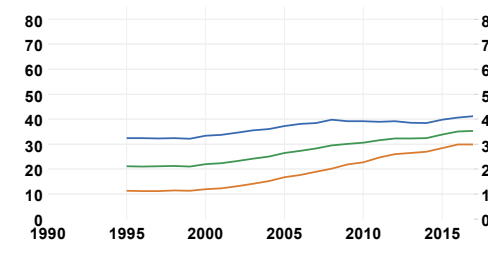

FRA

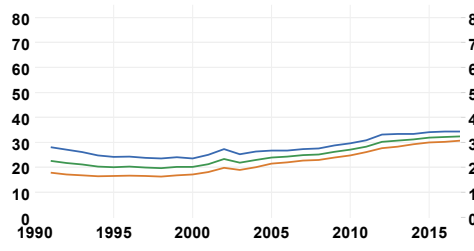

HUN

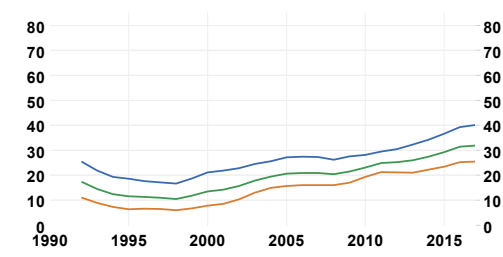

AUT

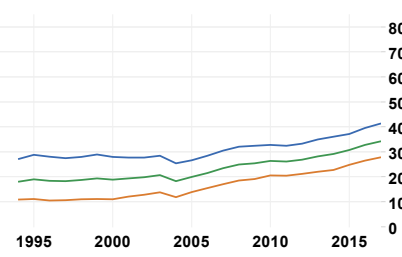

CHE
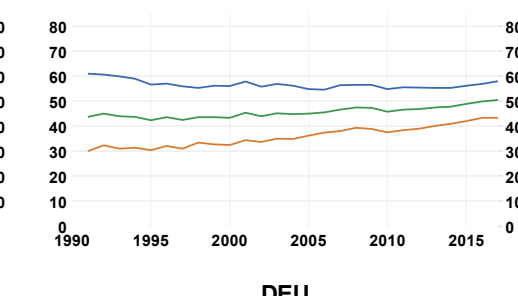

DEU

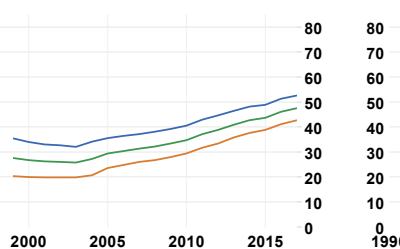

EST

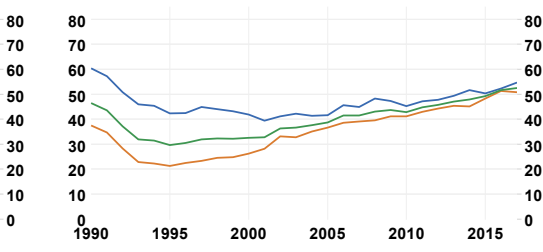

GBR

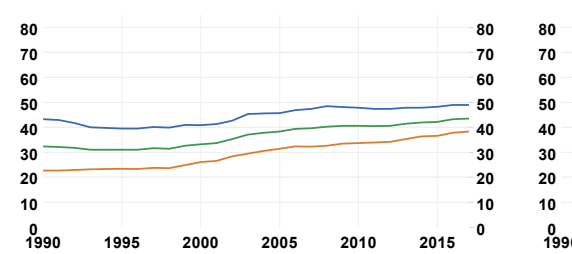

IRL

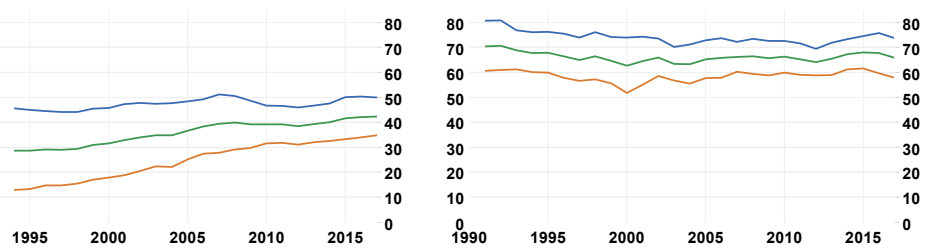

- Male _ Female — Total

BEL

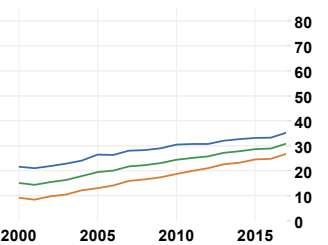

CHL
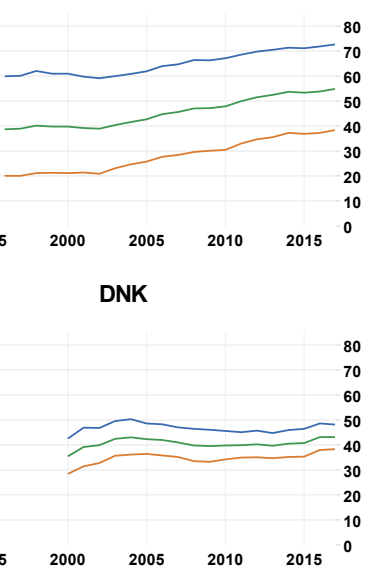

FIN
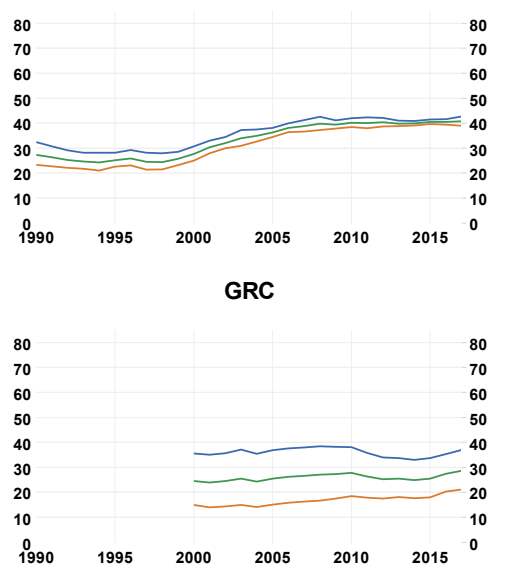

ISL

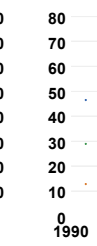

1 
ISR

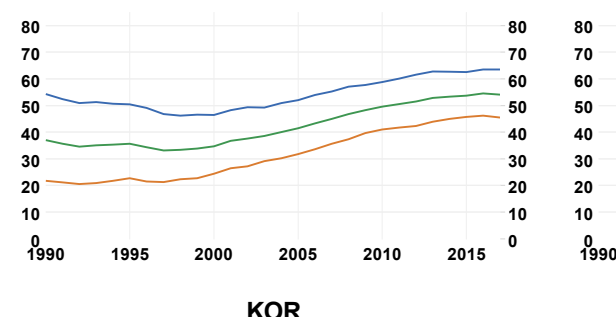

KOR

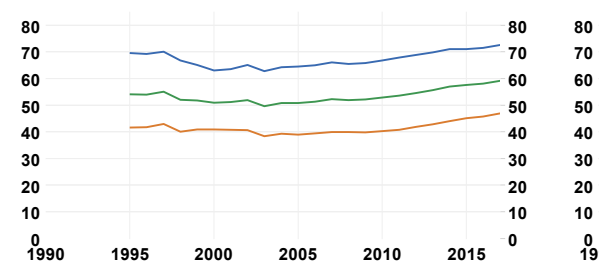

LVA

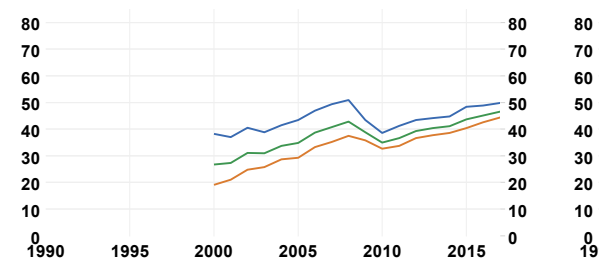

NOR

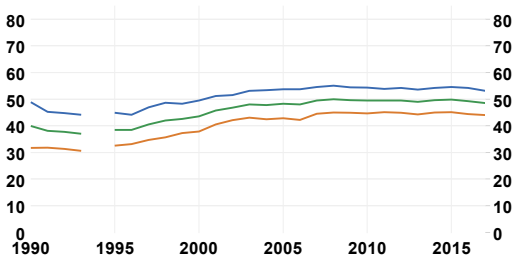

PRT

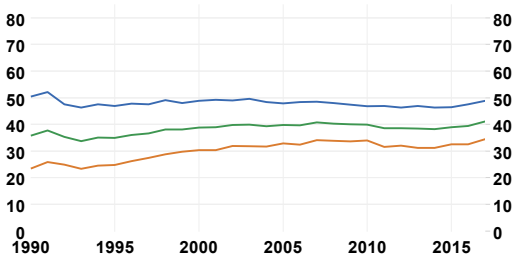

SWE

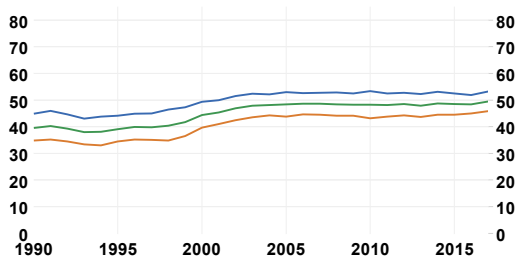

JPN

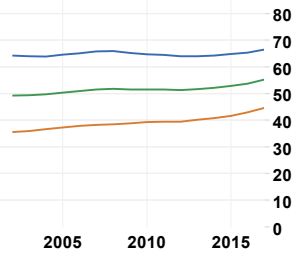

LUX

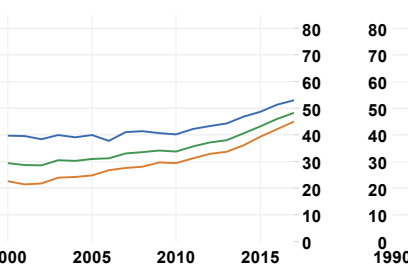

MEX

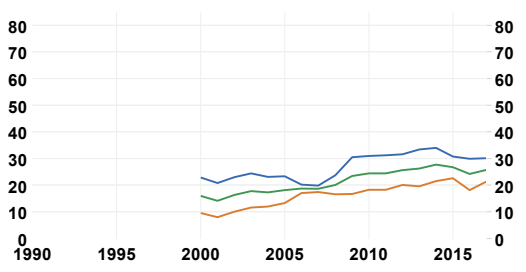

NLD

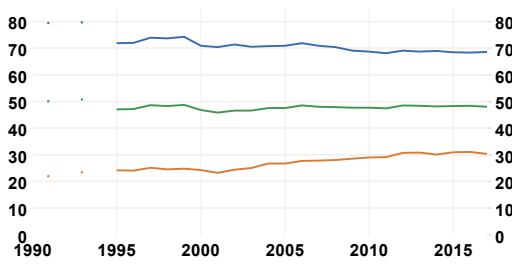

NZL

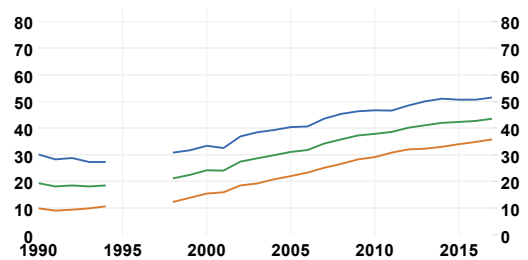

POL
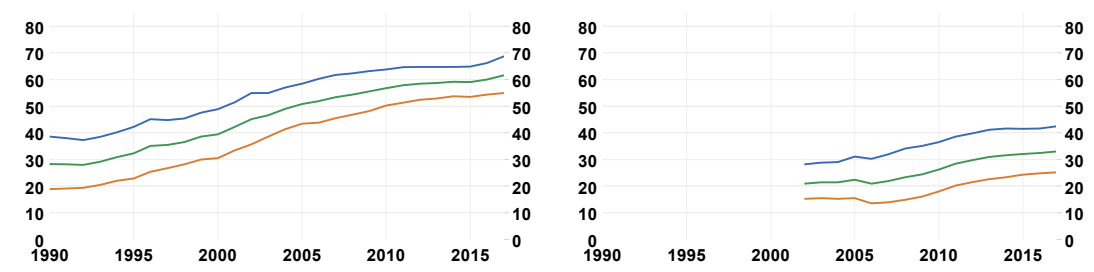

SVK

SVN

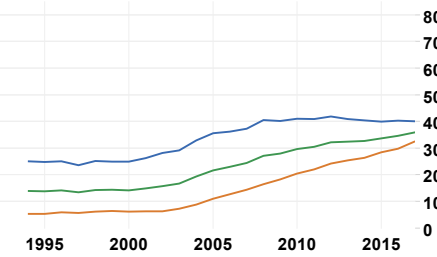

TUR

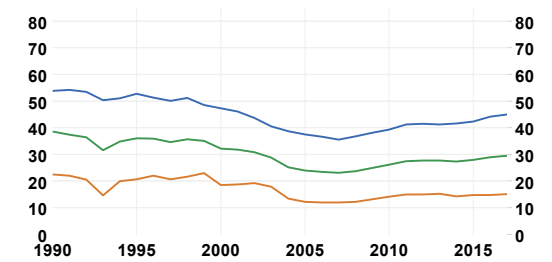

— Male — Female — Total

USA
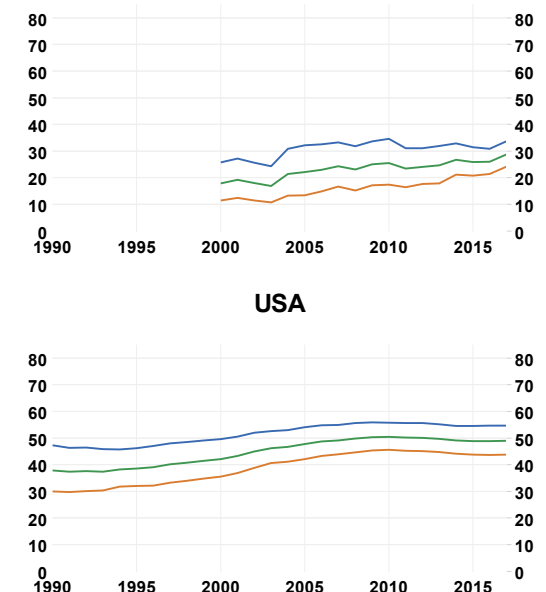

$\stackrel{0}{1990} 1995 \quad 2000 \quad 2005 \quad 2010 \quad 2015^{\circ}$

Source: OECD labour force statistics and authors' calculations. 


\section{Annex B. Description and source of variables}

\section{Dependent variable in regression models}

The unit of observation in the regression analysis is the population group specified by country, year, sex, level of educational attainment and single age bracket. The ages considered span 55 to 74. Educational attainment is classified as 'low', 'medium' or 'high' corresponding to, respectively, levels $0-2,3-4$ and 5-8 of the 2011 standard of the International Standard Classification of Education (ISCED).

The dependent variable is the labour force participation rate, defined as the labour force in a population group as a percentage of the population in that group. It is available for 26 countries with different time coverage (Table AB.1). Source: Eurostat data from Labour Force Surveys for the European countries, the Current Population Survey for the United States and the Statistics Canada Labour Force Survey for Canada.

Table B.1. Country and time coverage for the dependent variable

\begin{tabular}{llll}
\hline \multicolumn{1}{c}{ Country } & \multicolumn{1}{c}{ Period } & \multicolumn{1}{c}{ Country } & Period \\
\hline Austria & $1999-2017$ & Latvia & $1996-2017$ \\
Belgium & $1995-2017$ & Lithuania & $2002-2017$ \\
Canada & $1990-2017$ & Luxembourg & $1993-2017$ \\
Czech Republic & $2002-2017$ & Netherlands & $1992-2017$ \\
Denmark & $2002-2017$ & Poland & $2002-2017$ \\
Estonia & $2002-2017$ & Portugal & $1992-2017$ \\
Finland & $1992-2017$ & Slovak Republic & $2002-2017$ \\
France & $1992-2017$ & Slovenia & $2002-2017$ \\
Germany & $1992-2017$ & Spain & $1992-2017$ \\
Greece & $2002-2017$ & Sweden & $1992-2017$ \\
Hungary & $2002-2017$ & Switzerland & $1992-2017$ \\
Ireland & $1992-2017$ & United Kingdom & $1992-2017$ \\
Italy & $1992-2017$ & United States & $1990-2017$ \\
\hline
\end{tabular}

Explanatory variables in regression models:

- Unemployment rate and unemployment gap. The unemployment rate is the percentage of the labour force that is unemployed. The unemployment gap is defined as the non-accelerating inflation rate of unemployment (NAIRU) minus the unemployment rate. This indicator varies only in the country and time dimensions. Source: OECD Economic Outlook No. 104 database.

- Percentage of population group with tertiary education. The share of population with tertiary education is defined as the number of people with tertiary education as a percentage of the population in the relevant age/sex group. This indicator varies in the country, year, age and sex dimensions. Source: Wittgenstein Centre for Demography and Global Human Capital (2015). Since the original data are at the 5-year frequency and by 5 -year age group, local weighted regressions were used to obtain data at an annual frequency and by 1 -year age groups.

- Life expectancy at 65. Life expectancy at age 65 measures expected years of life remaining for a person aged 65 , according to age-specific mortality rates. This indicator 
varies in the country, year and sex dimensions. Source: United Nations World Population Prospects 2017. Since the original data are at the 5-year frequency, a local weighted regression was used to obtain data at an annual frequency.

- Above minimum retirement age. A dummy variable equal to 1 when age variable is equal to or greater than the minimum retirement age and 0 otherwise. The minimum retirement age is defined as the age at which an individual who entered the labour market at age 25 and had a full career becomes eligible for a (reduced) pension from a mandatory pension scheme. This indicator varies in the country, year and sex dimensions. Source: US Social Security Administration (2002-2018), Social Security Programs Throughout the World; MISSOC database (2017), Comparative Tables; OECD (2017), Pensions at a Glance: OECD and G20 indicators; and UN (2017), World Population Prospects: The 2017 Revision.

- Above normal retirement age. A dummy variable equal to 1 when age is greater than or equal to the normal retirement age and 0 otherwise. The normal retirement age is defined as the age at which an individual who entered the labour market at age 25 and had a full career becomes eligible for unreduced pensions from all mandatory pension schemes. This indicator varies in the country, year and sex dimensions. Source: Same as 'above minimum retirement age' variable.

- Pension wealth. The present value of all future pension income flows from mandatory (public and private) pension schemes for country $i$, sex $s$, age $a$, education level $e$ in year $t$, expressed as a multiple of annual earnings:

$$
\text { Pension wealth }_{i, s, a, e, t}=\frac{\sum_{j=a}^{100} s_{i, s, j, t} \frac{\text { ension }_{i, s, j, e, t}}{(1+r)^{j-a}}}{\text { earnings }_{i, s, a-1, e, t}}
$$

where $s$ is the probability of survival, pension is pension income accruing past the age of career end and $r$ is the real interest rate used to discount future payments, assumed to be $2 \%$. Pension income is simulated with country-year-age specific pension models based on statutory pension rules such as statutory retirement ages, penalty-bonus schemes for early or deferred retirement and minimum pensions. Because the dependent variable is the participation rate as opposed to the employment rate, the calculation excludes benefits from unemployment insurance schemes, even though such benefits are sometimes used to bridge the time gap between effective career end and pension eligibility. In this case, an individual is still officially considered part of the labour force. The simulations assume a full career at a constant share of average earnings after labour market entry, which differs by education and gender. This indicator varies in the country, year, sex, education and age dimensions. Source: Calculations based on information in US Social Security Administration (2002-2018), Social Security Programs Throughout the World; MISSOC database (2017), Comparative Tables; OECD (2017), Pensions at a Glance: OECD and G20 indicators; and UN (2017), World Population Prospects: The 2017 Revision.

- Pension replacement rate. This indicator measures to what extent pension income from mandatory retirement pension schemes replaces labour income upon career end. It is defined as the gross annual pension entitlement at career end as a percentage of final gross annual earnings. Pension income is simulated with country-year-age specific pension models based on statutory pension rules as described for the pension wealth 
variable. The indicator varies in the country, year, sex, age and education dimensions. Source: Same as 'pension wealth' variable.

\section{Population shares}

- Population shares by age, sex and education for the historical period. For European countries, shares of the 55-to-74 year-old population by single-age bracket, sex and education are based on Eurostat data. For Canada, Japan and the United States, population shares by age and sex are based on United Nations Population Division estimates and shares by education level are based on estimates by Lutz, Butz and KC $\left(2014_{[25]}\right)$. Sources: Eurostat, United Nations Population Division and Wittgenstein Centre for Demography and Global Human Capital. Since the original Wittgenstein Centre data are at the 5-year frequency and given by 5 -year age groups, multiple local weighted regressions are used to obtain 1-year frequencies in both the time and age dimensions.

- Population shares by age, sex and education for the projection period. Shares of the 55-to-74 year-old population by single-age bracket and sex are from the United Nations Population Division. Shares by education level are based on projections by Lutz, Butz and KC $\left(2014_{[25]}\right)$. Source: United Nations Population Division and Wittgenstein Centre for Demography and Global Human Capital, SSP2 scenario. Since the original Wittgenstein Centre data are at the 5-year frequency and given by 5-year age groups, multiple local weighted regressions are used to obtain 1-year frequencies in both the time and age dimensions. 


\section{Annex C. Individual country charts for pension wealth}

Figure C.1. Pension wealth from mandatory schemes by age of career end in 2017

Multiple of average earnings
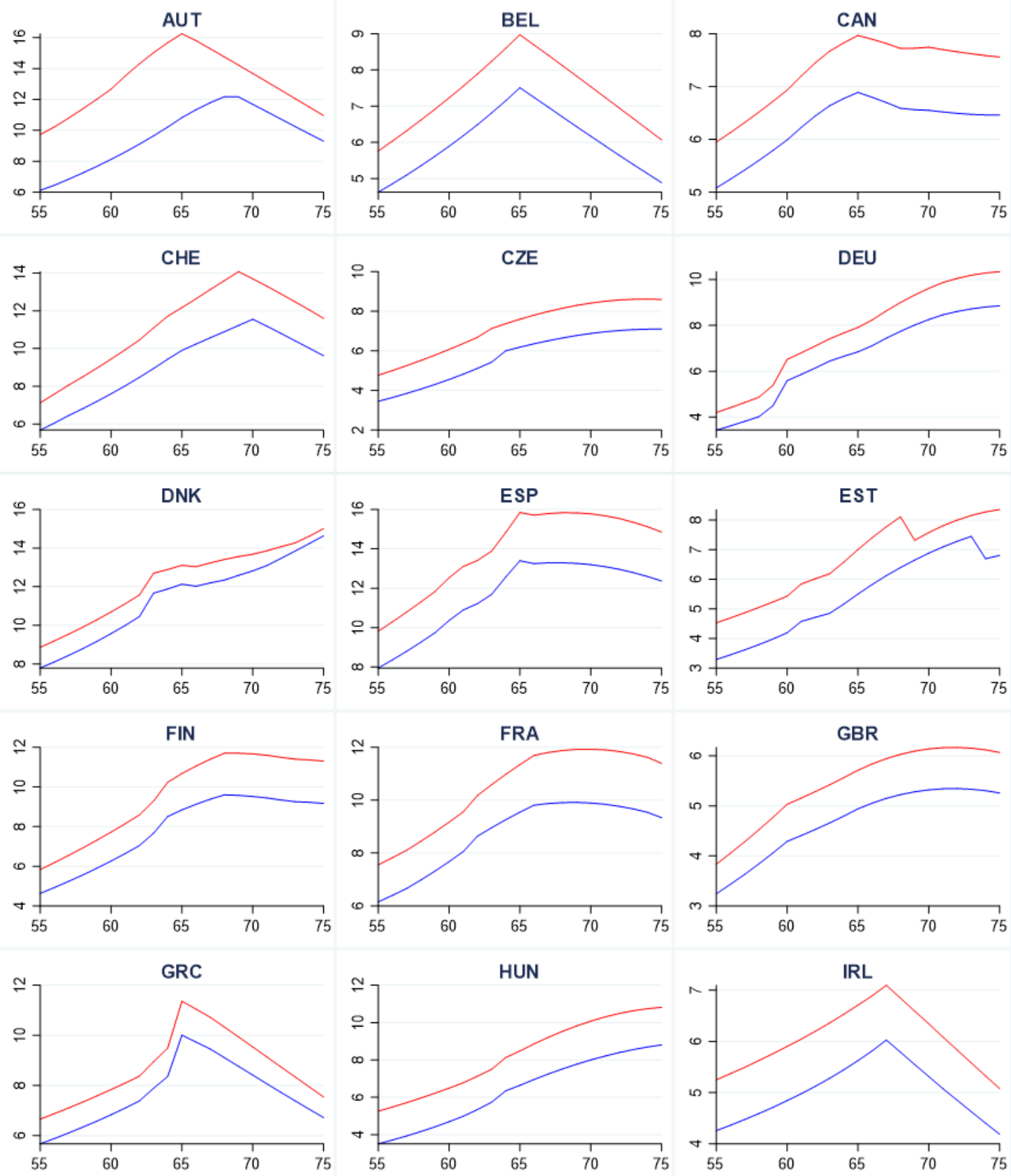

Men

Women 

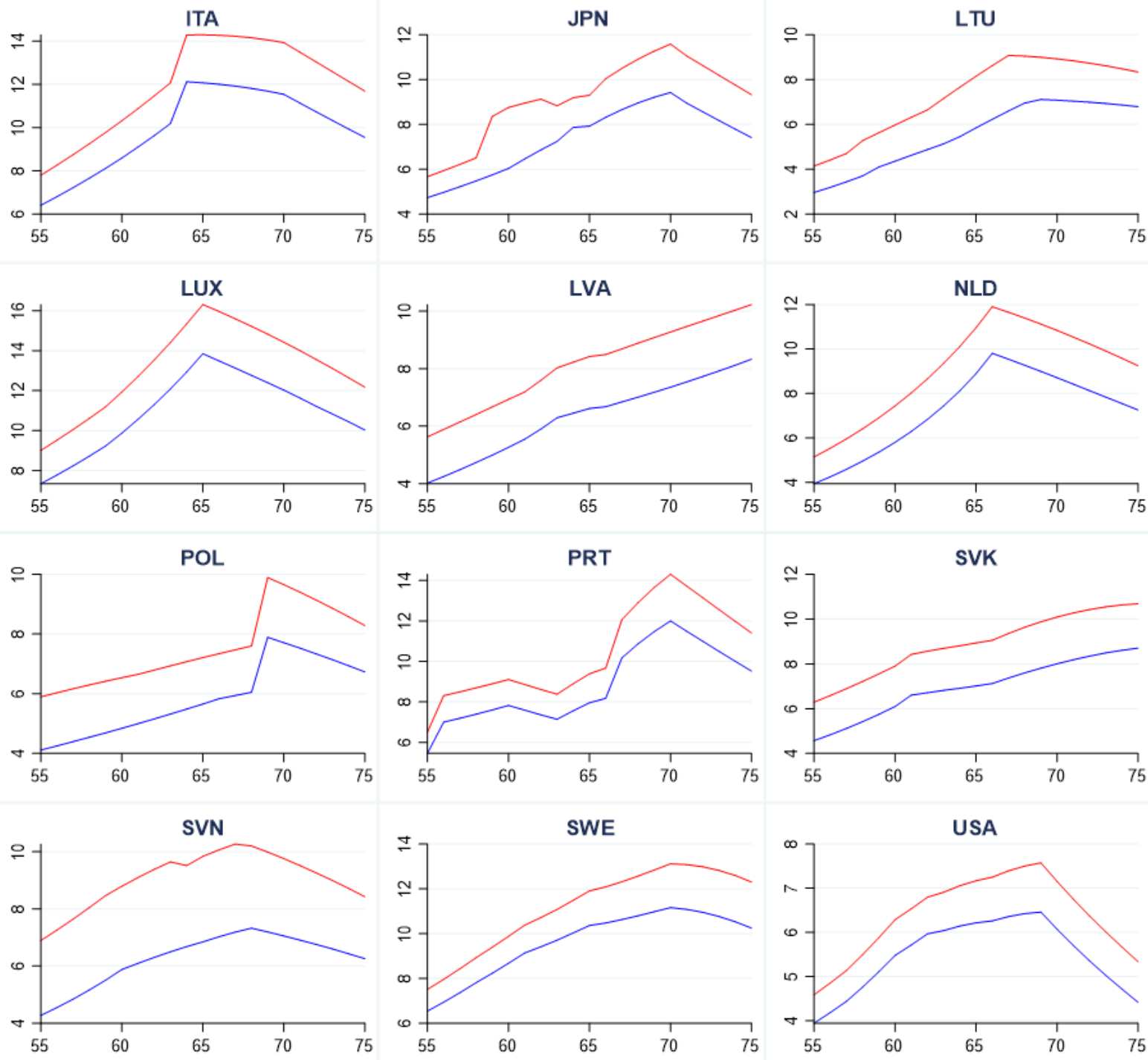

Men

Women

Note: The calculations apply to a worker with average earnings over a full career after entering the labour market at age 25 and includes old-age pensions from the main scheme but ignoring phased retirement, which allows a gradual labour market exit in some countries. The charts show a cross-section of estimates for a given year rather than a life cycle profile for a specific cohort, but the former is a close approximation to the latter.

Source: Calculations based on information in US Social Security Administration (2002-2018), Social Security Programs Throughout the World; MISSOC database (2017), Comparative Tables; OECD (2017), Pensions at a Glance: OECD and G20 indicators; and UN (2017), World Population Prospects: The 2017 Revision. 